\title{
FINITE ELEMENT ANALYSIS OF THE QC QUADRUPOLE MAGNET FOR THE SUPERCONDUCTING SUPERCOLLIDER*
}

\author{
Domenico Dell'Orco \\ Lawrence Berkeley Laboratory \\ University of California \\ Berkeley, CA 94720
}

October 20, 1989

*'This work was supported by the Director, Office of Energy Research, Office of High Energy and Nuclear Physics, High Energy Physics Division, U.S. Department of Energy under Contract No. DE-AC03-76SF(0)098. 


\section{ABSTRACT}

The Supercunducting Super Collider project will require the construction of nearly 9400 magnets of which 1800 are quadrupoles each $4.32 \mathrm{~m}$ long.

These magnets use niobium-titanium superconducting cables with a current of $6500 \mathrm{~A} /$ turn to get a high magnetic field gradient and focalize the particles beam.

After the $\mathrm{QA}$ and $\mathrm{QB}$ quadrupoles, a new quadrupole, called $\mathrm{QC}$, has been conceived. It is a $4 \mathrm{~cm}$ bore accelerator type, with a new collar design and a field gradient of $214 \mathrm{~T} / \mathrm{m}$ that is lower than the one in QA.

The new collar design consists mainly in a two pieces symmetrical and thicker collar which provides a complete support to the coils.

This paper will analyze the magnetic field and the stress and strain distribution.

The results show that this collar is a big improvement over the previous, especially in terms of stiffness, which is not explained only by the thicker collar but also by a different pole angle. 


\section{INTRODUCTION}

The purpose of this paper is to assess mechanically the new type of collar proposed for the SSC quadrupole magnets. A cross section of the QC magnet is shown in fig. 1. It has 8 turns in the inner layer and 13 turns in the outer layer. The coils are niobium-titanium superconducting cables wrapped in a kapton insulation tape with an epoxy outer layer. These cables are wound around the mandrel into eight coils each $4.32 \mathrm{~m}$ long using copper wedges. The coils are then put separately in the curing press to provide the polymerization of the epoxy. The coils are then assembled with the collar in the collaring press that compresses the collars and interlocks them inserting the keys. During the insertion of the keys, the press releases its compression in order to reduce the collaring stresses. To make the insertion easy, the keys are tapered. The collar is composed by two symmetrical pieces assembled in packs of 90 laminations each 0.0625 inch thick. The quadrupole collar is a self supporting structure which is designed to precompress the coils and to stand the Lorentz forces when the magnet is energized causing only small displacement and no separation between the coils and the collar. The collar is symmetrical and stiffer than the quadrupole QA [1] and provides a complete support to the coils while the previous could support the coils, at least at the poles, eaci two laminations only.

The collared coils are inserted in the iron yokes and surrounded by stainless steel skin. The iron yoke, used to improve and contain the magnetic field, does not have a structural function: the prestress and the Lorentz forces are supported only by the collar.

The magnet is inserted in a cryostat and cooled down to liquid helium temperature at which the $\mathrm{Nb}-\mathrm{Ti}$ is superconductor and then energized.

The QC quadrupole differs from QB [2] because its collar is $2 \mathrm{~mm}$ thinner and there is one more turn in the coils outer layer. Due to these two modifications the gradient has increased of $10 \mathrm{~T} / \mathrm{m}$. 


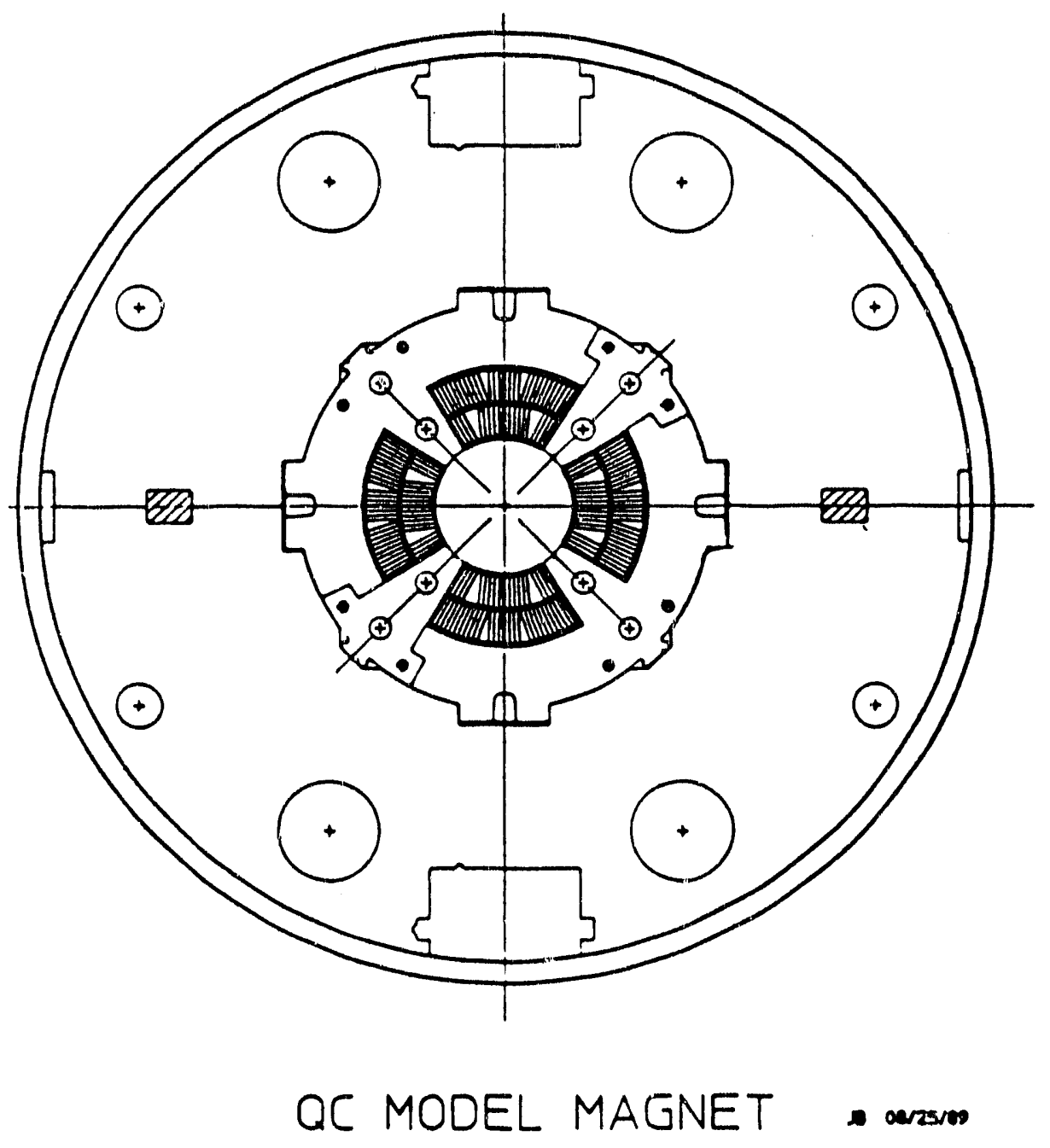

Fig. 1: cross section of the quadrupole magnet QC 


\section{FINITE ELEMENT MODELING}

The finite element model is a two layers model that represents a quarter of the magnet and two laminations of it (fig. 2-3).

The same model has been used to perform both magn:tic and mechanical analysis. For this reason also the bore tube has becn molelized in order to compute the magnetic field. The model consists of two layers of which the first is magnetic and mechanical and the second is only mechanical. A precise magnetic analysis requires much more elements than a structural one but in this case the magnetic analysis is mainly used as a tool to obtain easily the Lorentz forces on the mechanical model. On a much more refined mesh the magnetic analysis can be followed by a Fourier analysis to compute also the multipole components [3].

The computation is iterative because at the first iteration the magnetic field is evaluated and the Lorentz forces computed; in the following iterations the Lorentz forces are used to compute stresses and strains in the magnet, and to allow the convergency of the interfaces status (open or closed).

The magnetic analysis requires to set the current density on the coils, and specify the boundary conditions that are flux lines of the B vector perpendicular to the outer boundary ( infinite iron permeability) and flux lines parallel to the two radial boundaries (symmetry boundary conditions). The current density has been set to $6500 \mathrm{~A} /$ turn. The mechanical boundary conditions imply that the two radial boundaries are symmetry axes.

The finite element program ANSYS $\otimes$ [4] has been used to perform all the computations.

STIF13 2-d multi field solid element is used for the coils, collar, wedges and air; STIF52 three dimensional interface has been used to modelize the sliding and separation of the different materials inside the magnet. STIF 13 has UX, UY, TEMP and MAG as degrees of freedom and it uses the Newton-Raphson method to solve non linear problems.

An improvement done in this model is also the quasi-automatic meshing of the interfaces which allows to mesh them without the need of knowing the number of the nodes involved. This makes also much easier to vary the model and then do design more than analysis. The model contains interfaces between the coils, between the coils and the collars, and at the collar tabs.

The coils are joined so both the collar laminations by interfaces. There are no interfaces between each turn of the coils and between them and the copper 
wedges because this is believed to be a marginal detail.

The prestress has been modelized giving an interference to the interfaces between the coils and the collars at the poles. Some iterations are needed to find the interference which provides the prestress required. This interference takes into account two effects:

a) the dimensions of the used coils are obtained by a magnetic op:imization done on another software package and are valid if the coils have a constant stress of 5000 psi.

b) there is a G-10 shim inserted at the top of the coils.

The two layers of the collar are interlocked by the keys and by the pins. The keys have been modelized putting interfaces between the keyways of the two collar laminations and the pins simply merging the correspondent nodes on the two layers.

The inner coil-collar interfaces at the pole represent 30 mils of G-10 and 14 mils of kapton; they have also 1.46 mils of coils interference to take into account that the dimension of the coils in table 1 are with a stress of $5000 \mathrm{psi}$; an additional interference of 2 mils of aluminum is used and this means that the collar at the poles is 2 mils thicker than what required by the coils dimension (table 1) and the insulation layers.

The outer coil-collar interfaces at the pole represent 30 mils of G-10, 14 mils of kapton, 2.53 mils of coils interference and an additional interference of 2 mils of aluminum.

The outer coil-collar interfaces are 19 mils of kapton and 3 mils of TFE, 20 mils of brass and an interference of 2 mils. Here, the interference has been put to balance the radial displacement of the coils due to the prestress forces from the target position.

The interfaces between the coils represent 8 mils of kapton and 3 mils of TFE.

During the design, the model has been changed several times in order to consider different keyway geometries, collar tabs and to refine the mesh near the keyway.

The finite element model contains 3940 nodes and 4227 elements with a wave front of 359 and converges in $4-5$ iterations. The analysis has been performed with ANSYS Rev. 4.4 on the VAX 8650 of the Lawrence Berkeley Laboratory. ANSYS Rev. 4.4 has an improved meshing capability over the previous revision. This is very useful because every region can now be meshed with quadrilaterals 
and only a small number of triangles. This increases the accuracy of the results being the triangles less accurate than the quadrilaterals.
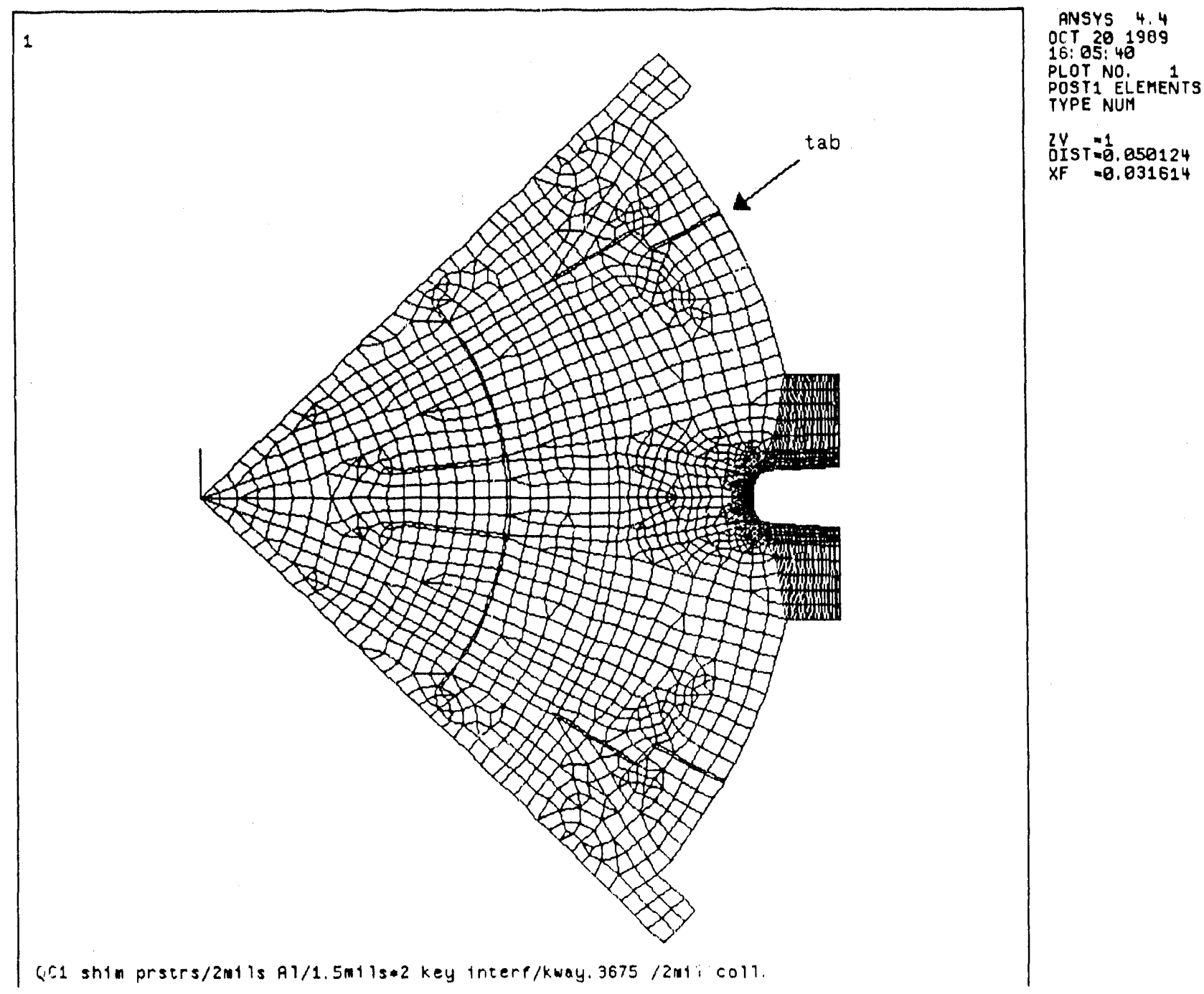

Fig. 2: meshing of the quadrupole magnet QC (first layer) 


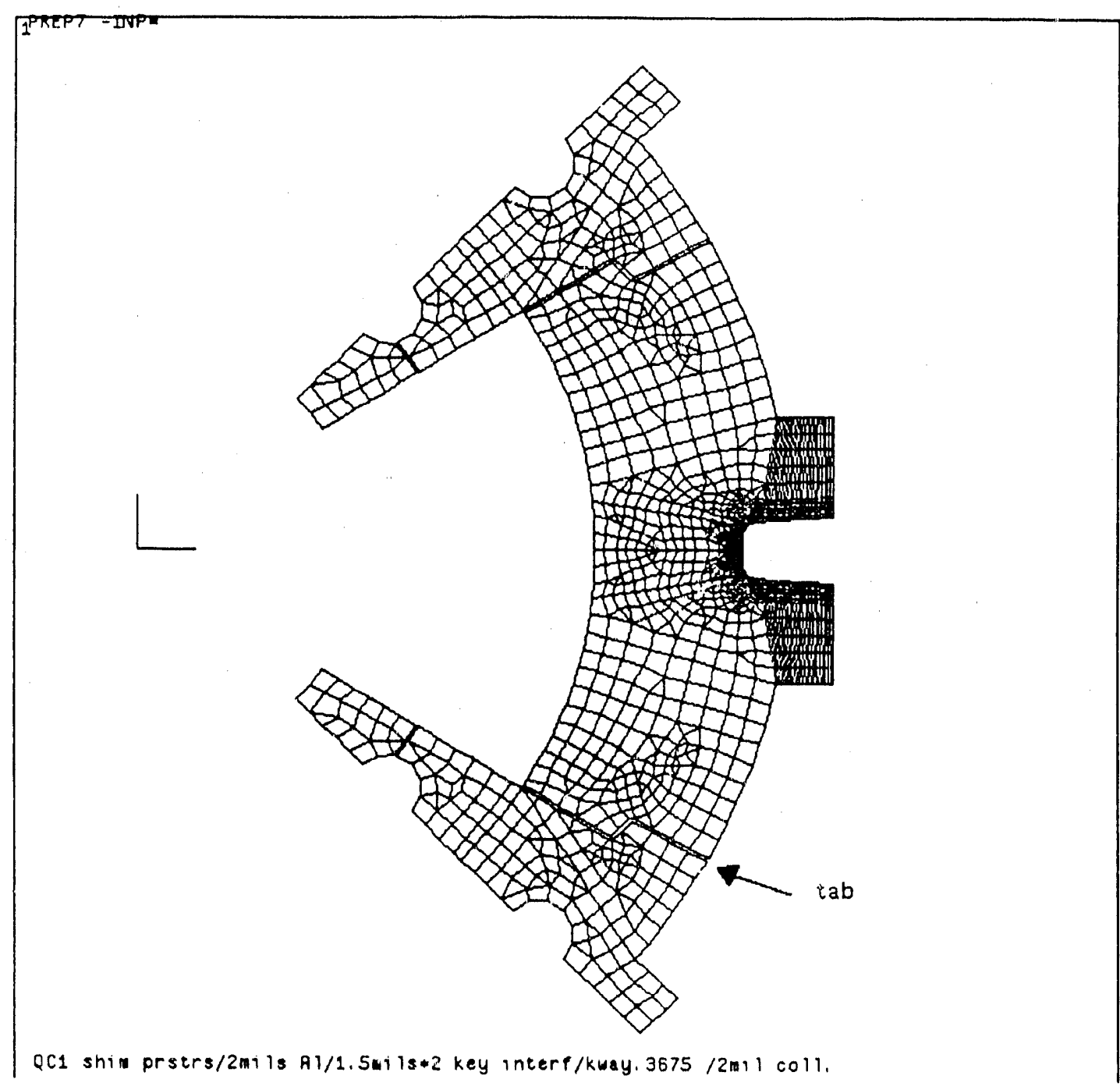

PNSYS 4.4
OCT 23.1989
10.45 10: $45: 14$ TYPE NUF

24 -1

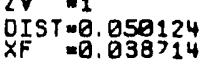

Fig. 3: meshing of the quadrupole QC (second layer) 


\section{DESIGN VARIABLES AND LOAD CASES}

The purpose of the design is to have a prestress of $\sim 5000$ psi at the middle plane of the coils, to minimize stresses and displacements, and have a residual compression at the top of the coils when the magnet is energized.

During the design, the shim has been initially set to have the required prestress at the middle plane.

To minimize the displacements, the interference between the two layers at the keyway has been changed. It was observed that the displacements could be minimized setting the interference to close the gap at the collar tabs.

The finding of the right prestress has required some iterations because it depends by the shim and by the key interference.

The model has also been modified to have a finer mesh near the keyway (fig. 26) and the fillet radius varied and finally set to 0.06 irich.

Also some modifications of the collar tabs geometry (tabs inverted and "two way" tab) have been considered but no appreciable variation has been found.

The collar inner radius has been reduced of 2 mils to balance the outward displacement of the coils and has increased the coils prestress at the middle plane from 4600 psi to 5700 psi.

Finally when all the parameters have been fixed, two load cases were run:

a) prestress only;

b) prestress and Lorentz forces (6500 A/turn). 


\section{CALCULATION ASSUMPTIONS}

The assumptions used in this study are the following :

a) the iron has an infinite permeability and then there is no iron saturation;

b) the collar is free standing;

c) all the materials are homogeneous, isotropic and linearly elastic;

d) the coils have no hysteresis;

e) there is no sliding between the coils and the copper wedges;

f) there is no friction;

g) plane stress analysis is done;

h) the cool down does not induce any stress as proved by strain gauges measurements on other magnets with aluminum collar.

The assumption a) does not influence the Lorentz forces computation.

The Young's moduli used in this study are shown in table 1.

In fig. 4 the key-points of the coils, whose dimensions are listed in table 2, are shown. The coils dimensions include not only the bare conductor but also the kapton-epoxy insulation.

In fig. 5 it is shown the compression test done on a stack of the coils to be used in QC, and the Young's modulus is derived. Taking into account the stiffness of the coils support, the Young's modulus is $1.31 \mathrm{Mpsi}$.

\begin{tabular}{|c|c|}
\hline Material & Young's modulus (Mpsi) \\
\hline coil & 1.31 \\
\hline aluminum & 10.2 \\
\hline copper & 17.4 \\
\hline G-10 & 1.45 \\
\hline brass & 17.4 \\
\hline TFE & 0.058 \\
\hline kapton & 0.51 \\
\hline
\end{tabular}

Table 1: Young's moduli 


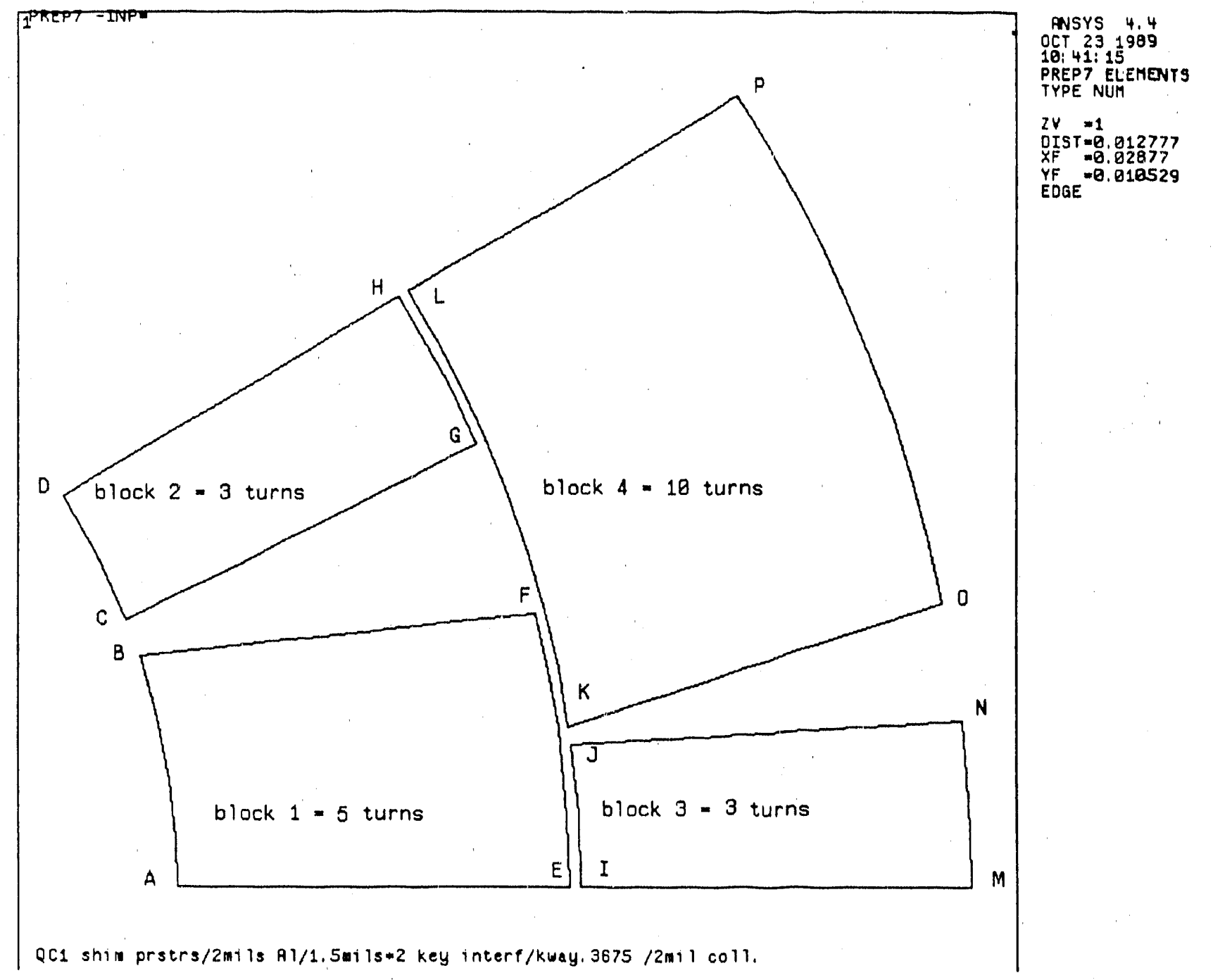

Fig. 4: inner and outer coils 


\begin{tabular}{|c|c|c|}
\hline Point & $\mathrm{x}$ (inch) & $\mathrm{y}$ (inch) \\
\hline $\mathrm{A}$ & 0.7872 & 0.0040 \\
\hline $\mathrm{B}$ & 0.7581 & 0.2447 \\
\hline $\mathrm{C}$ & 0.7402 & 0.2807 \\
\hline $\mathrm{D}$ & 0.6725 & 0.4094 \\
\hline $\mathrm{E}$ & 1.1832 & 0.0040 \\
\hline $\mathrm{F}$ & 1.1518 & 0.2877 \\
\hline $\mathrm{G}$ & 1.0906 & 0.4653 \\
\hline $\mathrm{H}$ & 1.0101 & 0.6164 \\
\hline $\mathrm{I}$ & 1.1944 & 0.0040 \\
\hline $\mathrm{J}$ & 1.1869 & 0.1492 \\
\hline $\mathrm{K}$ & 1.1919 & 0.1700 \\
\hline $\mathrm{L}$ & 1.0195 & 0.6222 \\
\hline $\mathrm{M}$ & 1.5904 & 0.0040 \\
\hline $\mathrm{N}$ & 1.5821 & 0.1750 \\
\hline $\mathrm{O}$ & 1.5662 & 0.2993 \\
\hline $\mathrm{P}$ & 1.3571 & 0.8293 \\
\hline
\end{tabular}

Table 2: coils dimensions 


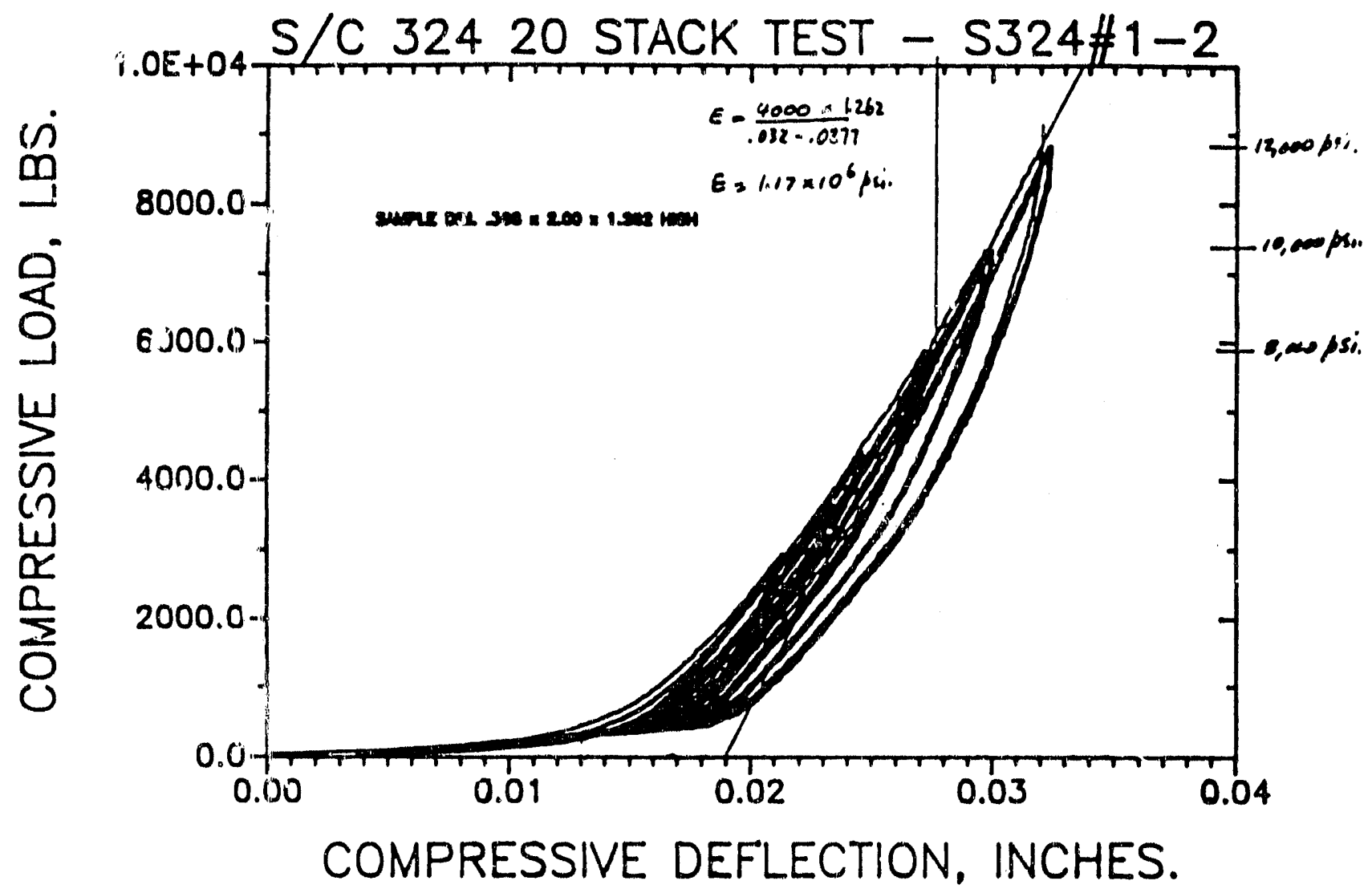

Fig 5: compression test on the coils 


\section{RESULTS}

In fig. 6 the flux lines of the magnetic field are shown, and in fig. 7 the Lorentz forces on the coils.

In table 3 the Lorentz forces acting in an octave of the quadrupole on sach block of conductors are shown.
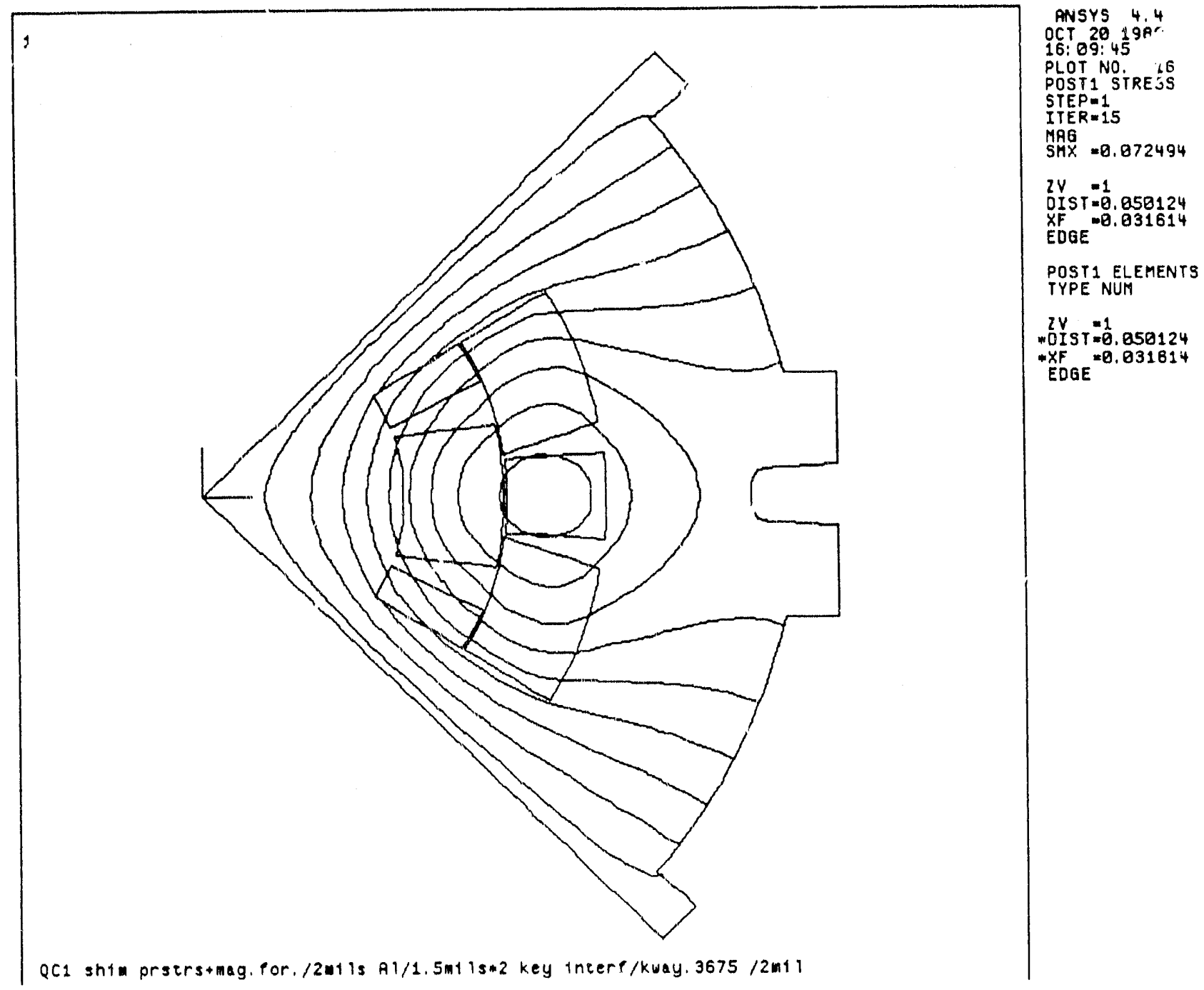

Fig. 6: flux lines of the magnetic field 


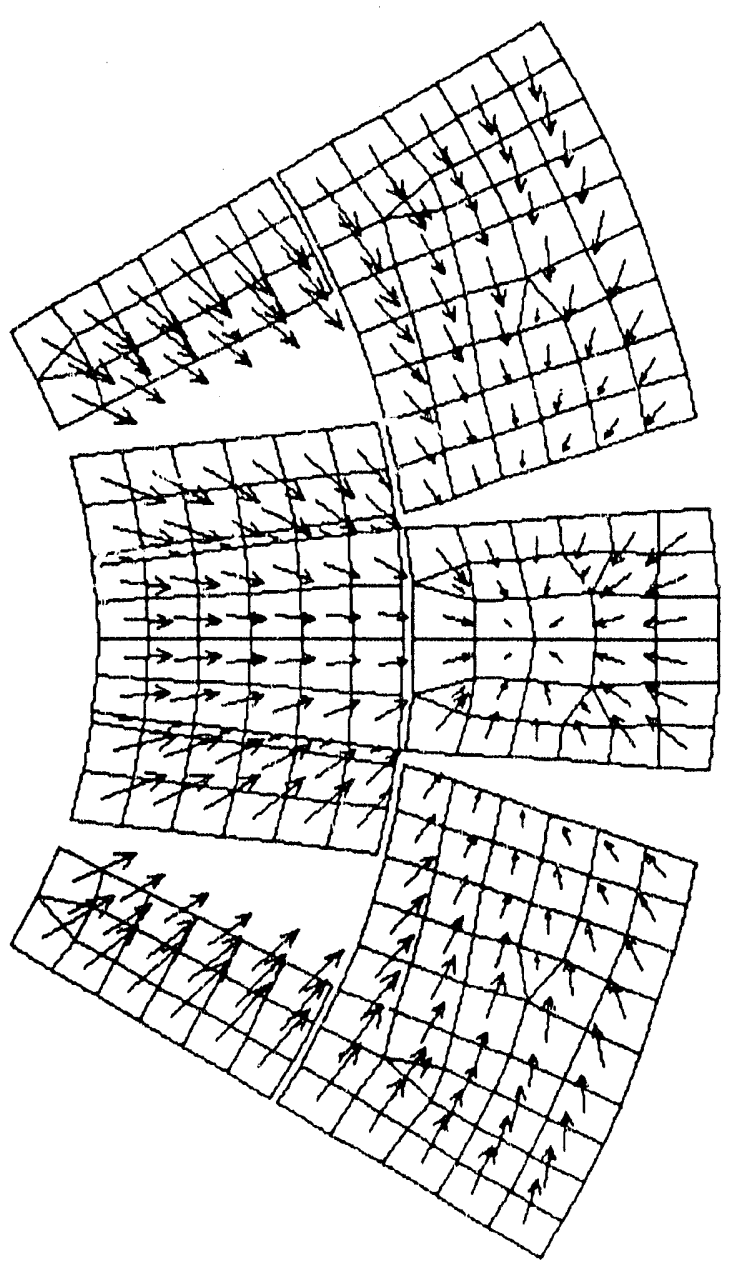

PNSYS
OCT 4.4
16:

16: Q9: 38 .

PLOT NO. 15
POST VECTOR

STEP 1
ITER $=15$

ITER=15

EMAQM 1780

1256

1820

2384
2947

3511

4075

4838

5766

2V -1

OIST $=0.023164$

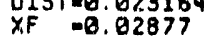

QC1 shim prstrs+mag. for. $/ 2 \mathrm{mils}$ Al/1.5m 18*2 key interf/kway. $3675 / 2 \mathrm{mI}$

Fig. 7: Lorentz forces on the coils 


\begin{tabular}{|c|c|c|}
\hline block & Fx (lb/inch) & Fy (lb/inch) \\
\hline 1 & 496 & -196 \\
\hline 2 & 334 & -278 \\
\hline 3 & -61 & -126 \\
\hline 4 & 200 & -707 \\
\hline
\end{tabular}

Table 3: Lorentz forces on the coils

In fig. 8 the variation of the magnetic field along the horizontal axis is shown.

This diagram, which is not too accurate because the mesh is coarse, shows a magnetic field gradient of $214 \mathrm{~T} / \mathrm{m}$.

In fig. 9 the value of the magnetic field in the beam tube and in the coils is shown. The maximum value of the flux density in the coils is $4.49 \mathrm{~T}$. 


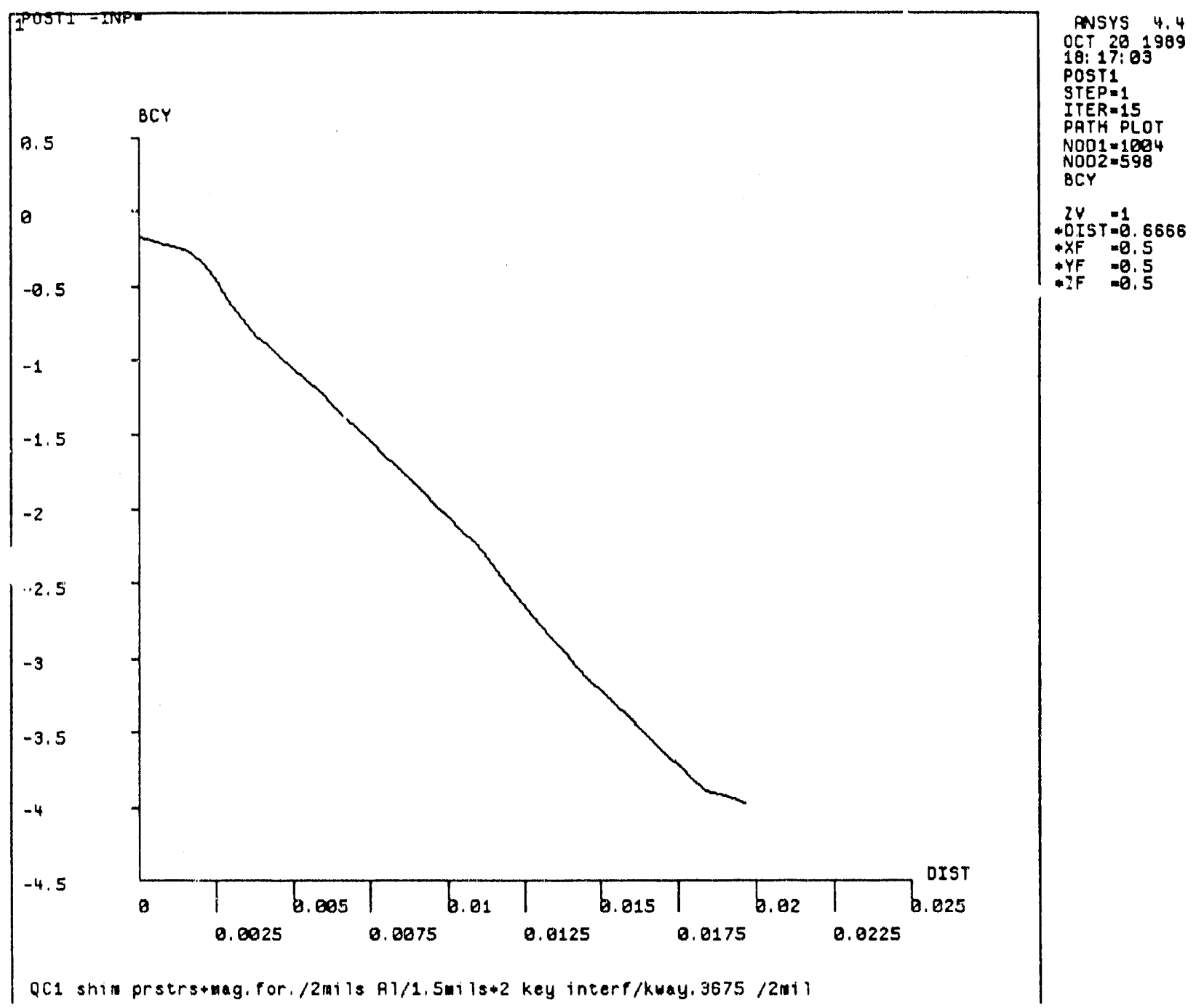

Fig. 8: flux density $B$ in the tore tube along the horizontal axis ( $T$ vs. $m$ ) 


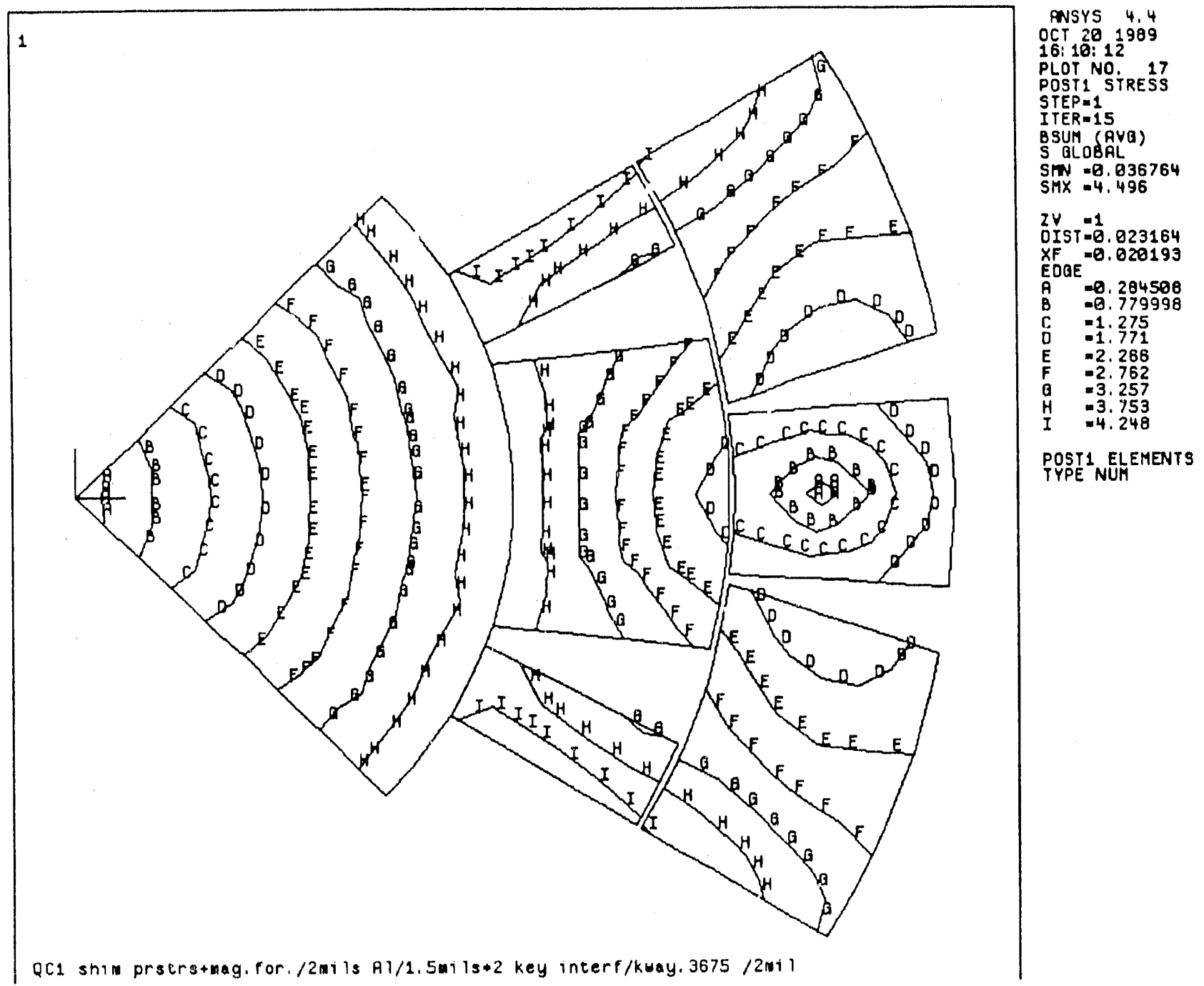

Fig. 9: values of the flux density $B$ in the bore and in the coils (T)

The radial and azimuthal stresses in the coils, the Von Mises stress in the collar, the radial and azimuthal displacements of coils and collar under the two load cases (prestress with and without Lorentz forces), are shown in fig. 10-27.

The radial displacement of the coils at the point $M$ (fig. 4), from the dimension reported in table 1 , is 2.3 mils under prestress only and 2.8 mils with the Lorentz forces. 
The aluminum collar, at the middle plane near the keyway, has a radial displacement of 4.2 mils with prestress and 4.7 mils with the Lorentz forces.

The Lorentz forces seem to increase the displacements slightly because they also decrease the prestress in the coils and then the displacements due to it.

The value of this effect seems to be correlated to the pole angle.

The radiai displacement of the collar on the $45^{\circ}$ axis is 2.3 mils with prestress and 2.2 with the Lorentz forces.

In fig. 24-25 the diagrams of the azimuthal stress at the pole and the middle plane of the coils with and without Lorentz forces are shown.

In fig. 24 it is shown that at the middle plane the Lorentz forces do not increase the prestress on the inner coil but only on the outer :oil of 900 psi.

In fig. 25 it is shown that at the coils poles, the Lorentz forces decrease the prestress of 1200 psi leaving a residual compression of 2800 psi.

The gradient of azimuthal stress at the pole is mainly due to the shim, which is applied at the pole. This is caused by the fact that the shims have constant thickness along the radius and that the coils behave like a thick cylinder. However it is important that also when the magnet is energized there is a 2800 psi residual compression at the pole and then no separation and possibility of motion that could cause bad training of the magnet.

Fig. 16, 23, 27 show that the Von Mises stress is low in the collar except in the keyway, where it reaches $130 \mathrm{kpsi}$. This value beyond the yield stress of the Al 7075/T6, in the elastic model, is not a problem because many dipoles at the same point reach $200 \mathrm{kpsi}$ without causing any visible sign of plasticity. This means that the plastic zone, if it exists, is small.

In fig. 28 it is also shown how the 2 mils shim at the collar inner radius moves the coils inward and the collar outward decreasing in this way the displacements of the coils and improving the field quality.

If the keys and the keyways have the same size, the coils prestress causes the separation of the two half collars increasing in this way the displacements, then in the model the key and the keyways have an interference which varies from 1 to 5 mils along the keyway axis.

The key is also tapered with an angle of $2.95^{\circ}$ and the keyways are offset from the middle plane in order to have the contact with the key only on one side. 


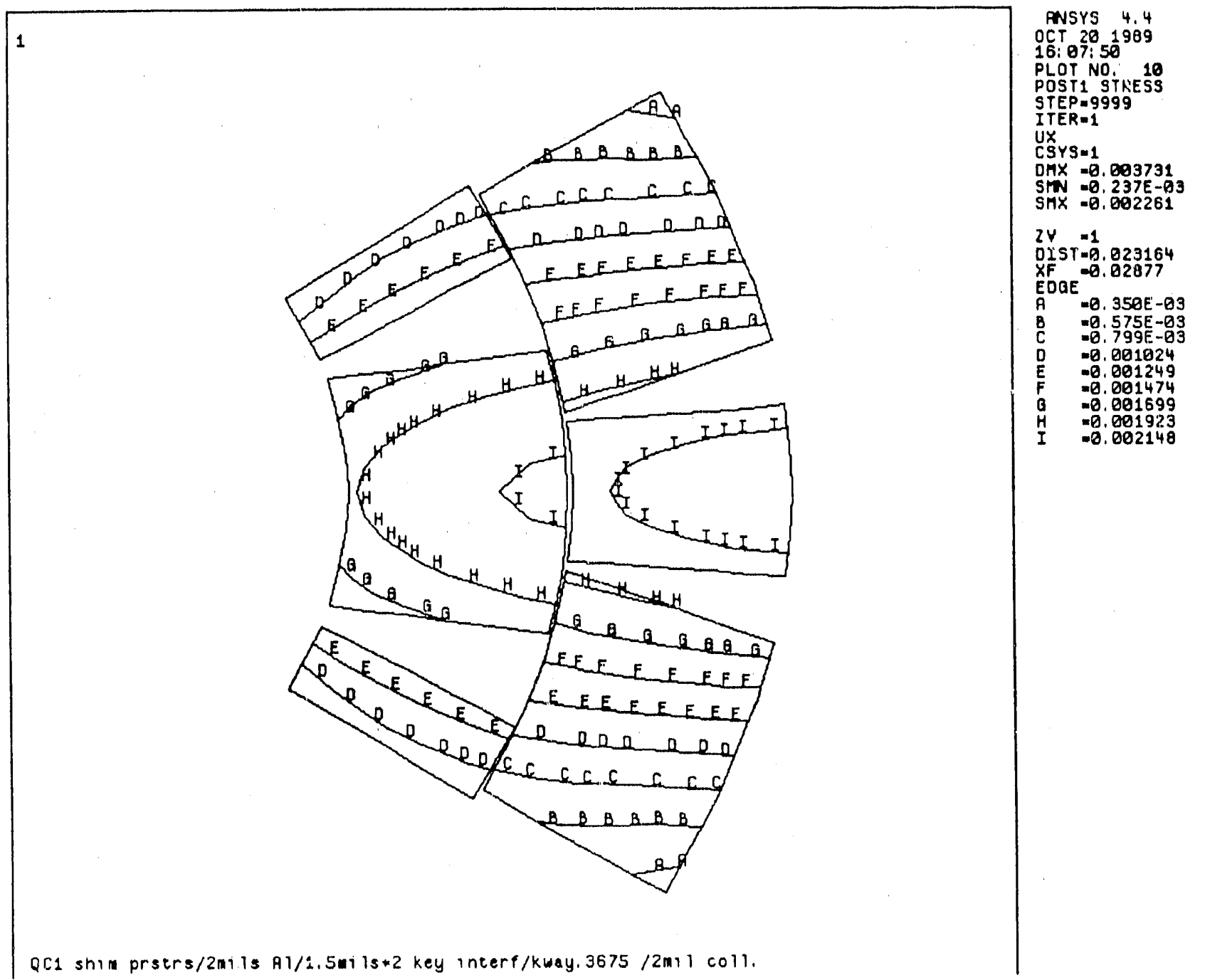

Fig. 10: radial displacements of the coils with prestress only (inch) 


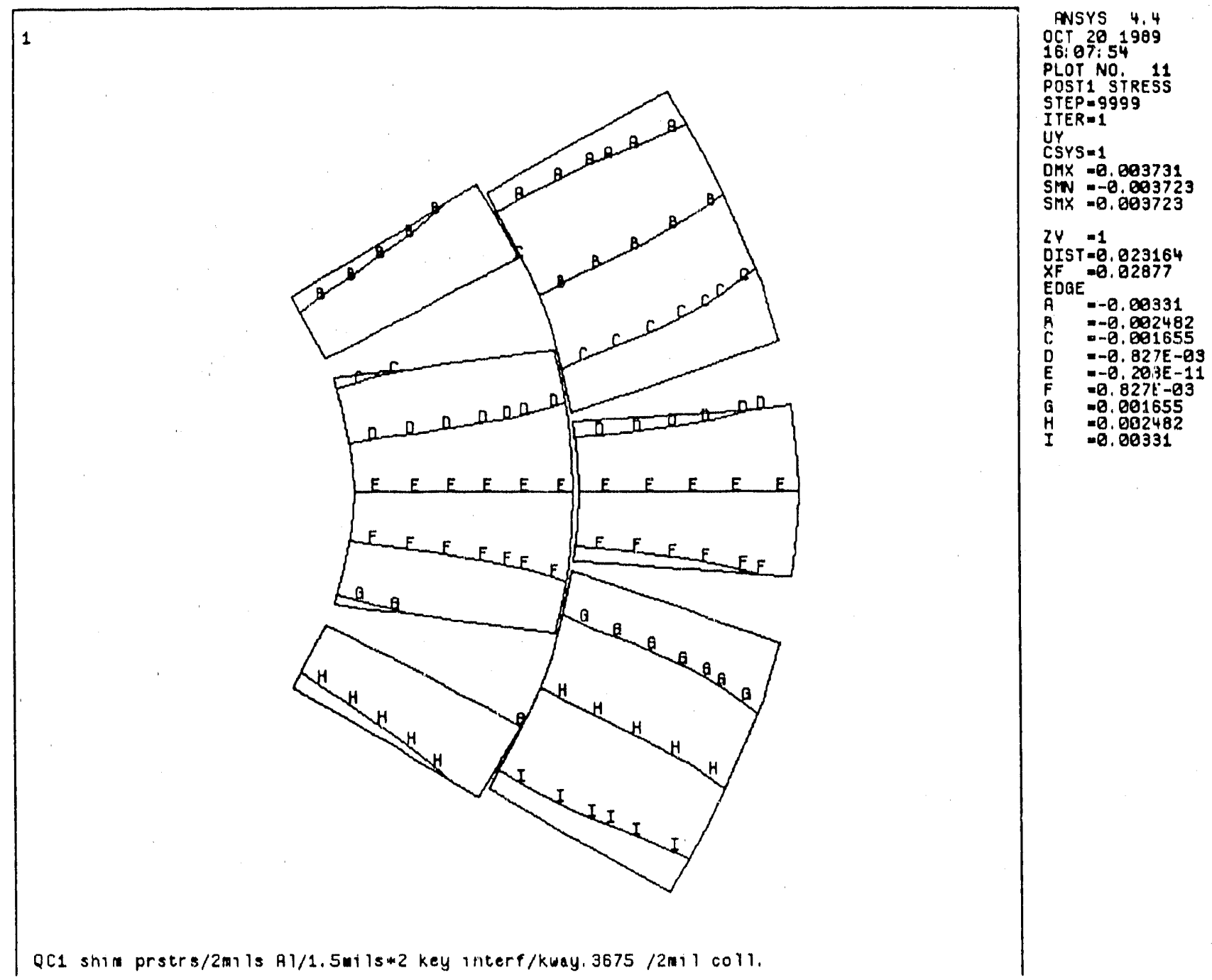

Fig. 11: azimuthal displacements of the coils with prestress only (inch) 


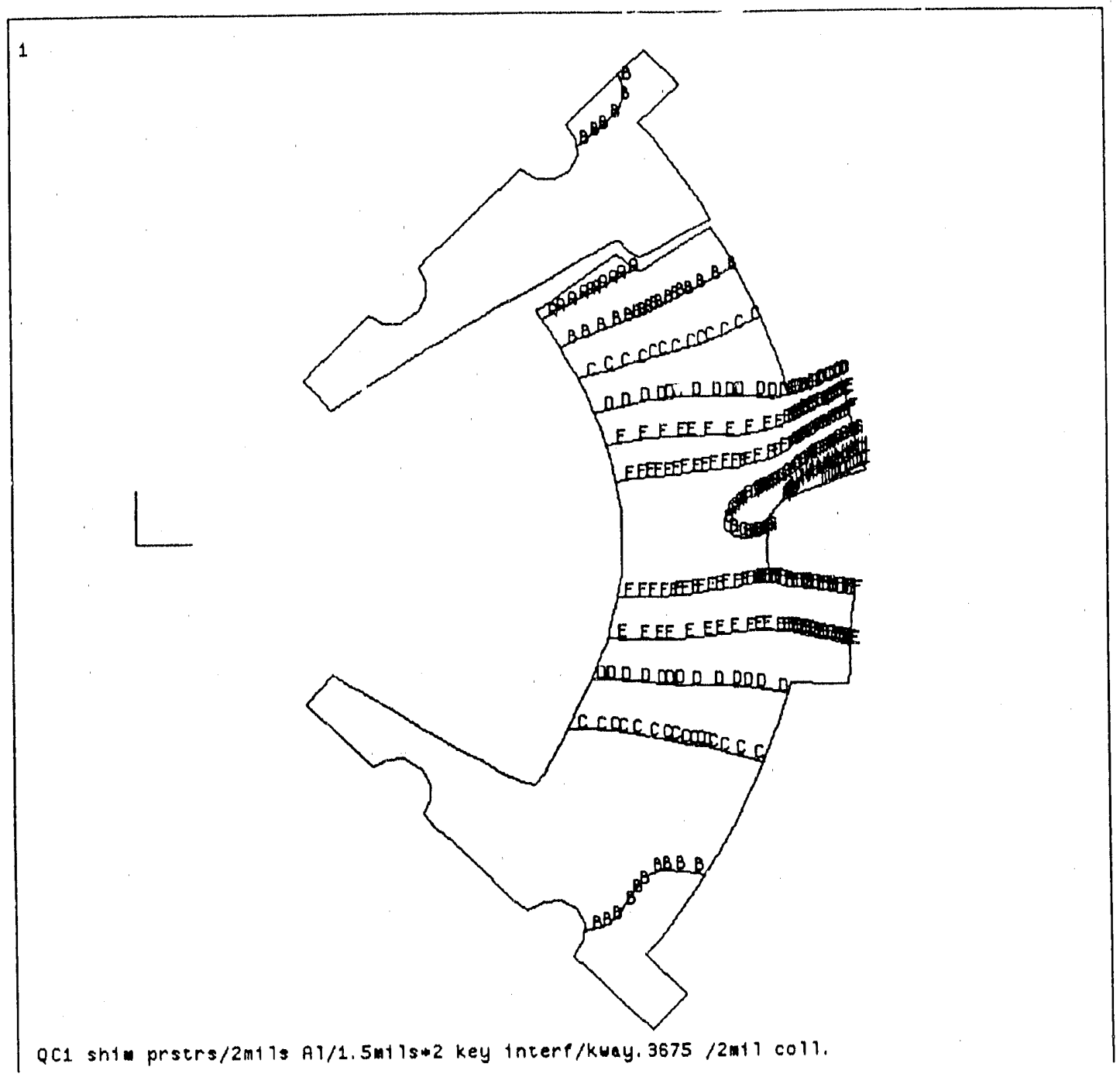

ANSYS 4.4

OCT 201989

18: 08 : 02

PLOT NO. ${ }^{1}$,

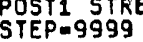

ITER $=1$

CSXY

MYX $=0.007005$

SW $=0.001319$

$\operatorname{sMX}=0.005396$

$2 V-1$

DIST $=0.050124$

$X F=Q .838714$

$\mathrm{A} \quad \mathrm{m} \theta .001545$

A. $\quad m 0.001545$ 0.001998
$=0.002451$

$=0.002904$

$=0.603357$

$=0.00301$

$=8.004263$

$=0.004716$

$=0.005169$

Fig. 12: radial displacements of the collar with prestress only (inch) 


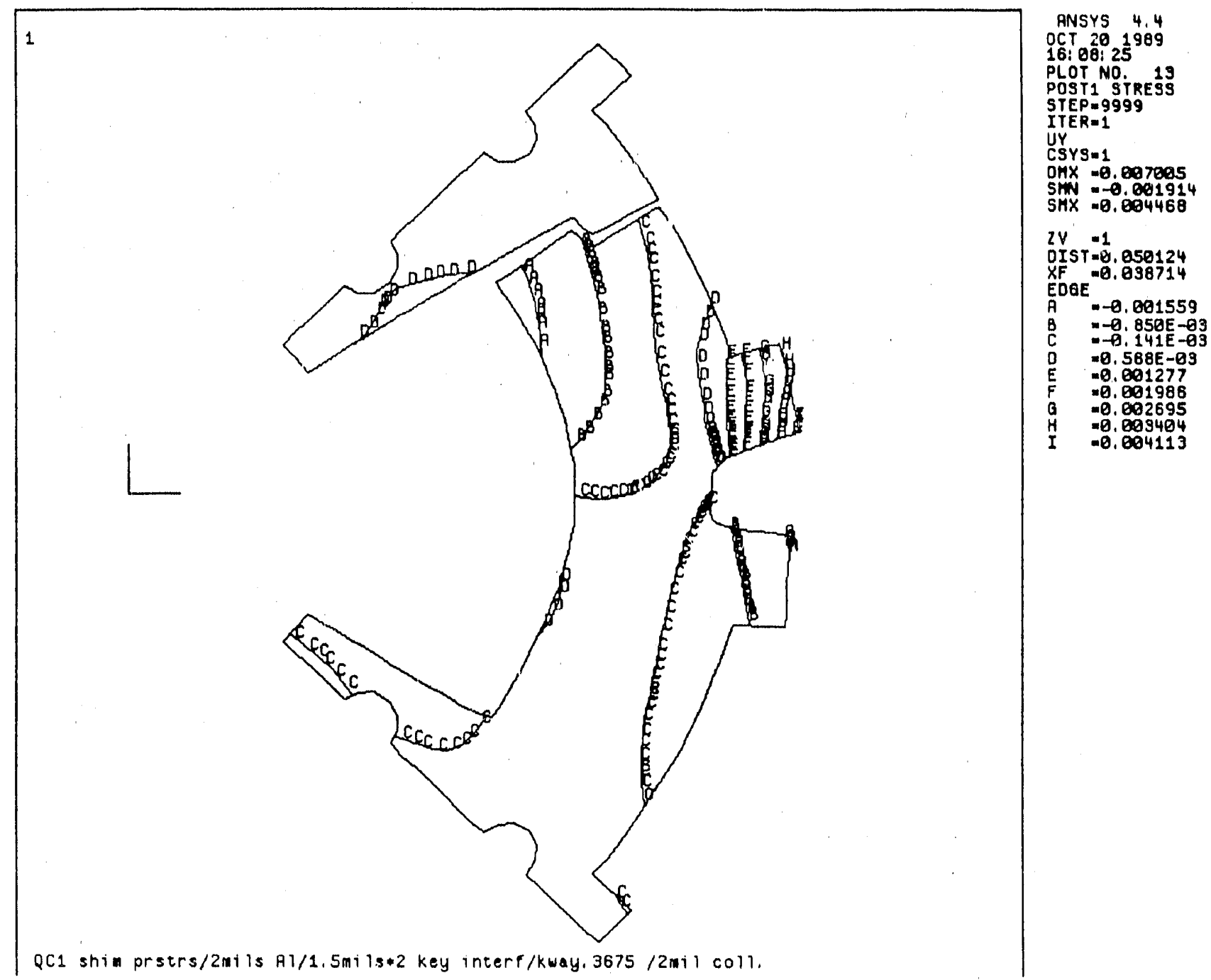

Fig. 13: azimuthal displacements of the collar with prestress only (inch) 
1

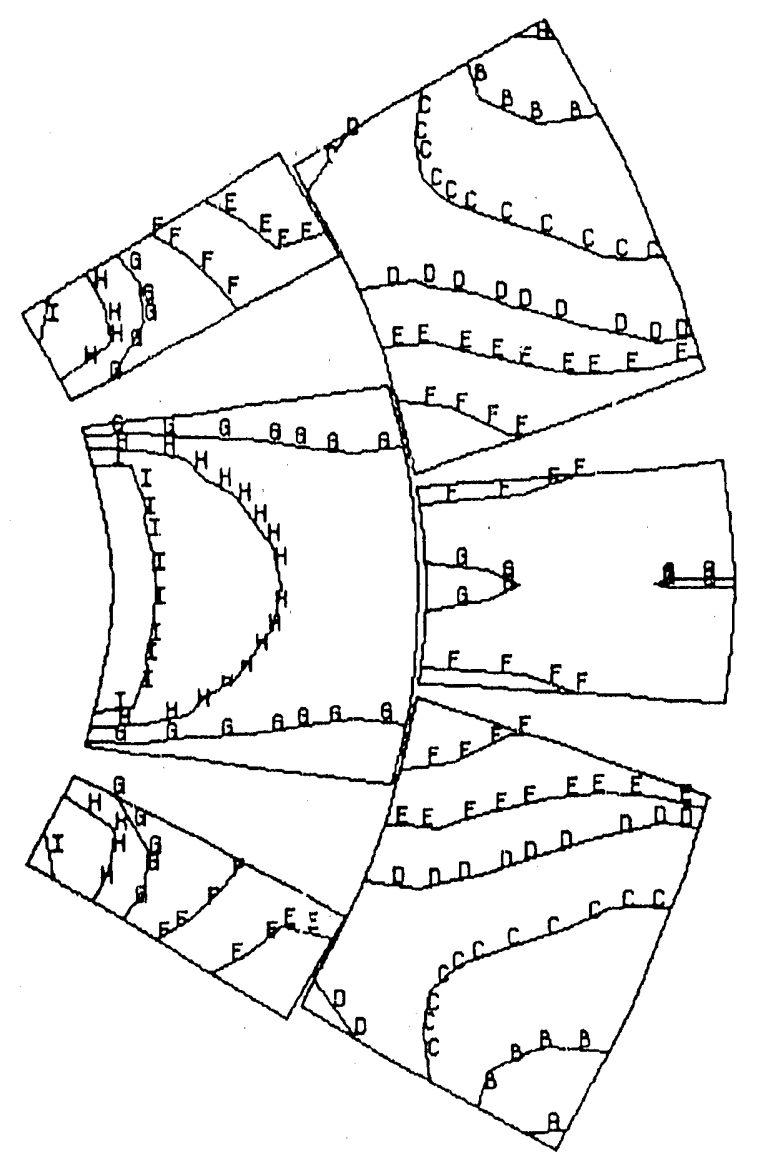

QC1 shim prstrs/2nt is A1/1,5m11s*2 key theer /kway. $3675 / 2 n+1$ coll.

ANSYS 4.4

OCT 201989

PLOT NO, 6

POST1 STRESS

STEP $=9999$

ITER $=1$ (AYA)

SSYS AVA

DHX $0.137 E-07$

SiN $=-4209$

SHX $=-120.649$

2V $=1$

OIST-0.029164

$X F \quad-0.02877$

EDQE $=-3976$

B $\quad=-3523$

D -2615

$-2162$

$=-1708$

$-1255$

$=-891.019$

Fig. 14: radial stresses in the coils with prestress only (psi) 
1

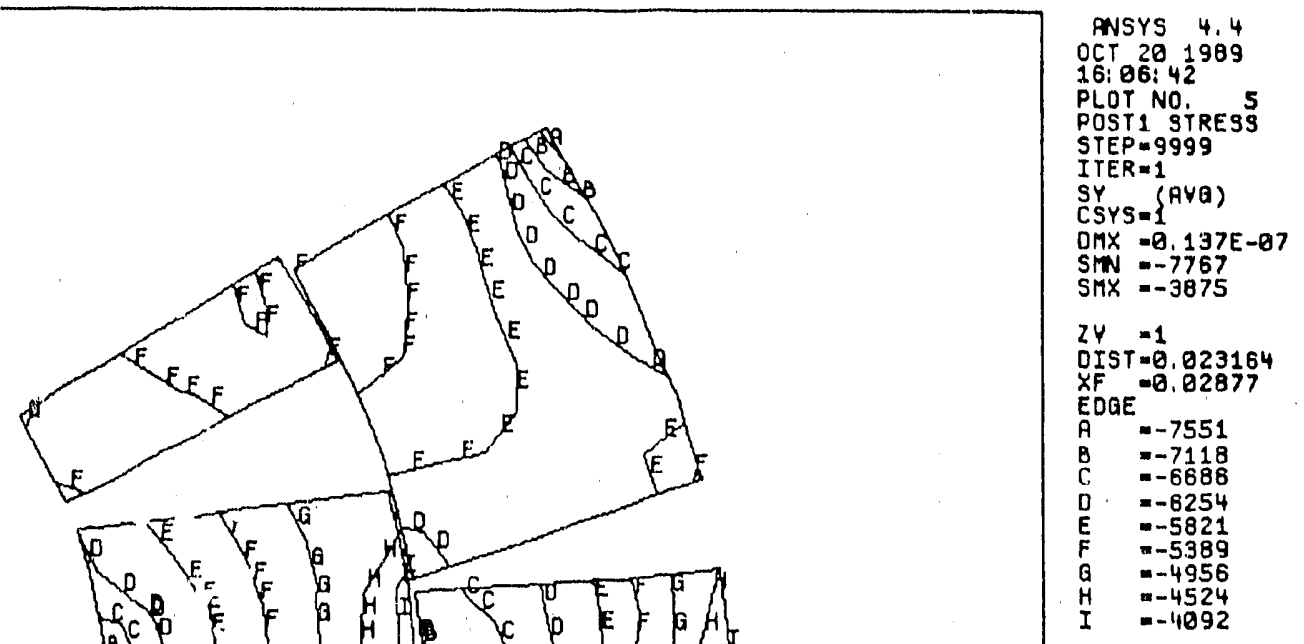

QC1 shin prstrs/2mi1s R1/1.5mi1s*2 key interf/kway, $3675 / 2 \mathrm{mil}$ coll.

Fig. 15: azimuthal stresses in the coils with prestress only (psi) 


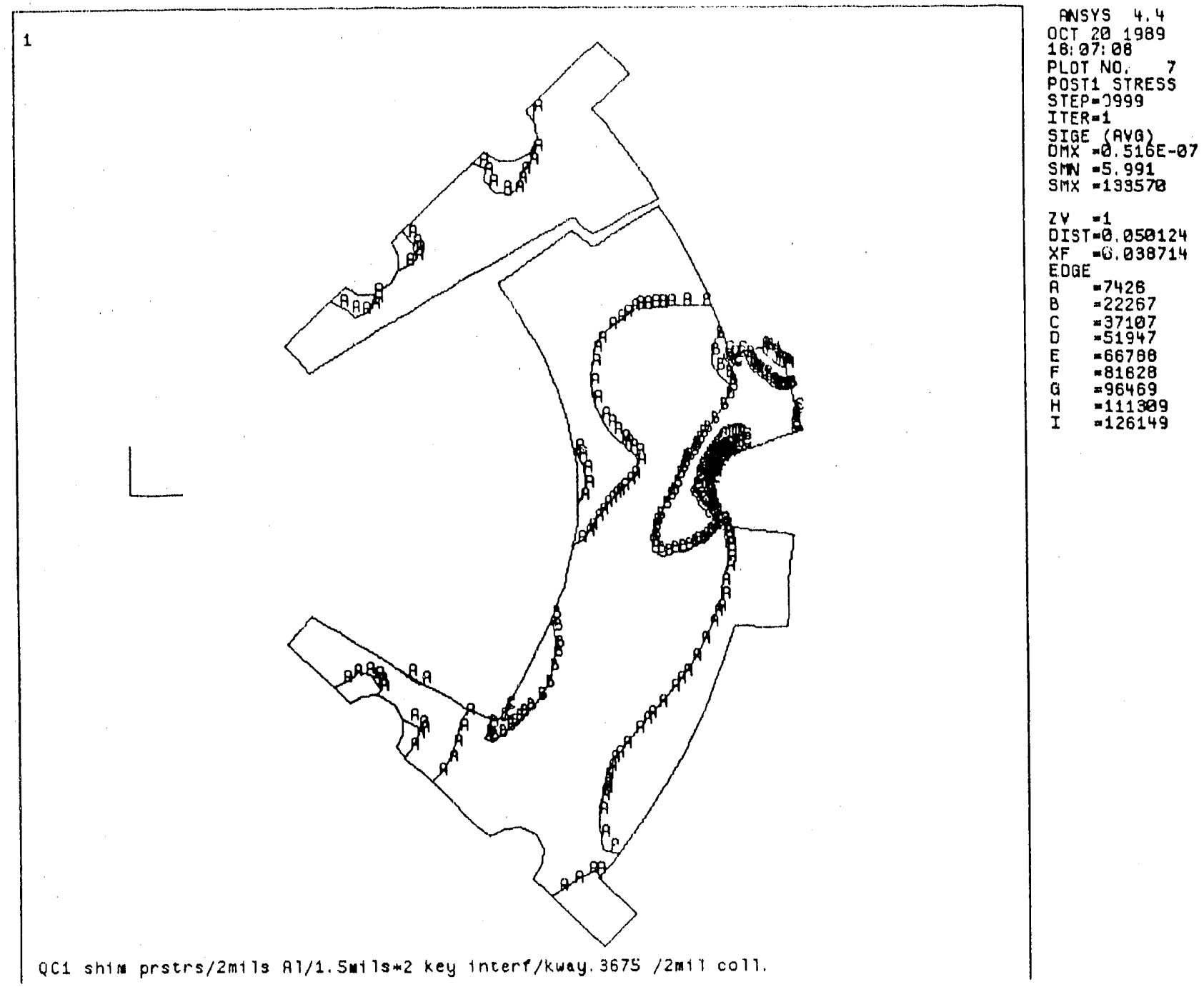

Fig. 16: Von Mises stress in the collar with prestress only (psi) 


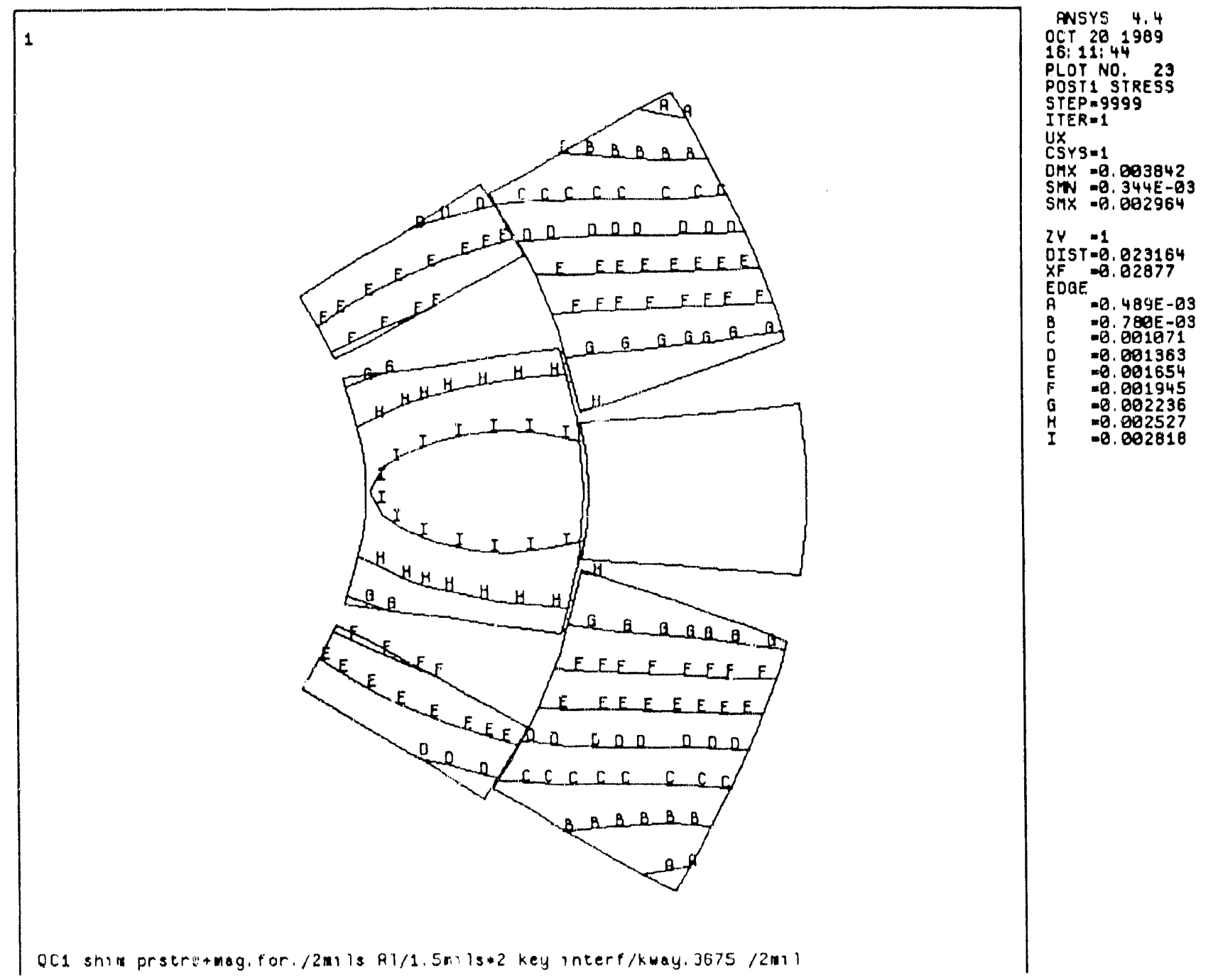

Fijg. 17: radial displacements of the coils with prestress and Lorentz forces (inch) 


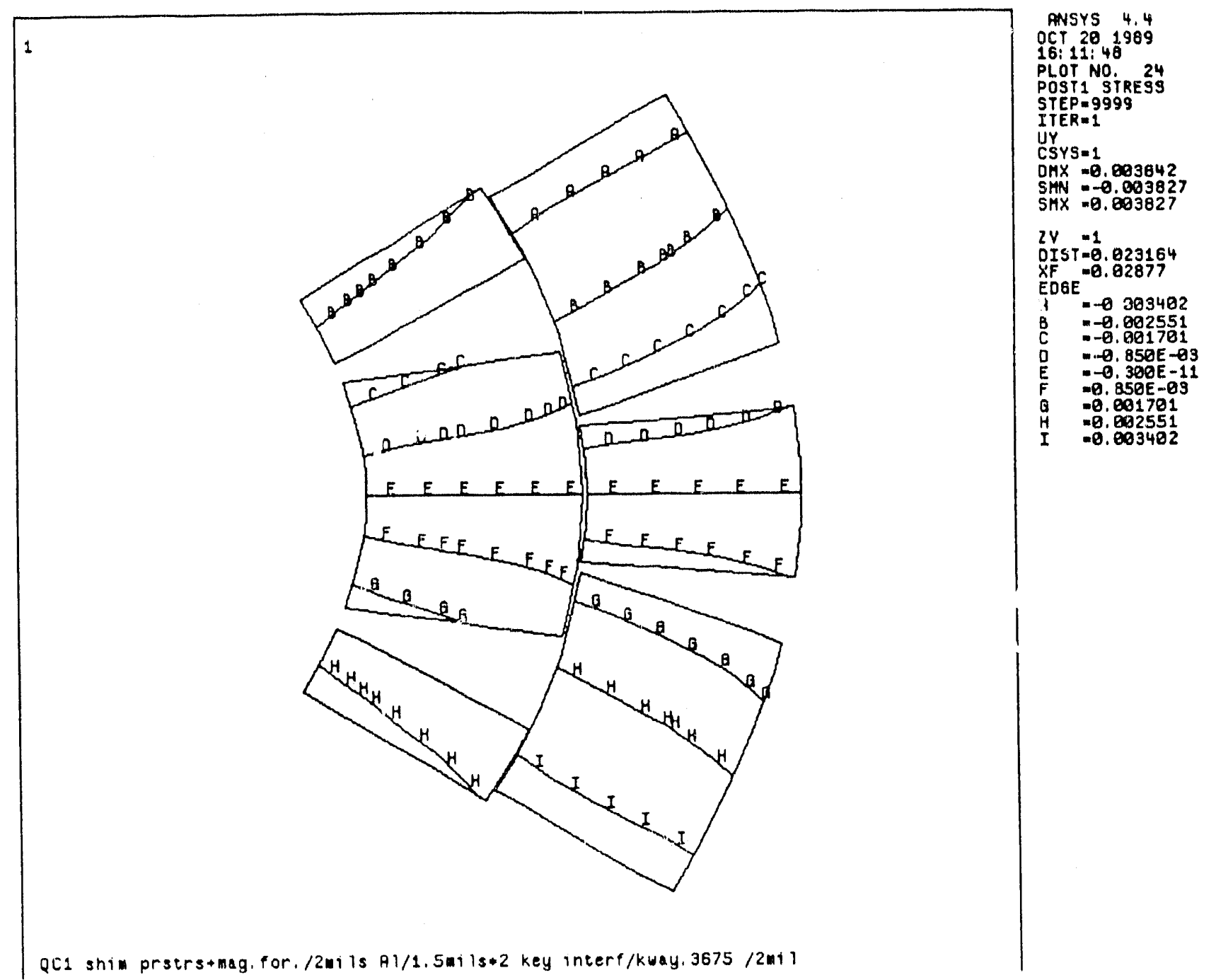

Fig. 18: azimuthal displacements of the coils with prestress and Lorentz forces (inch) 


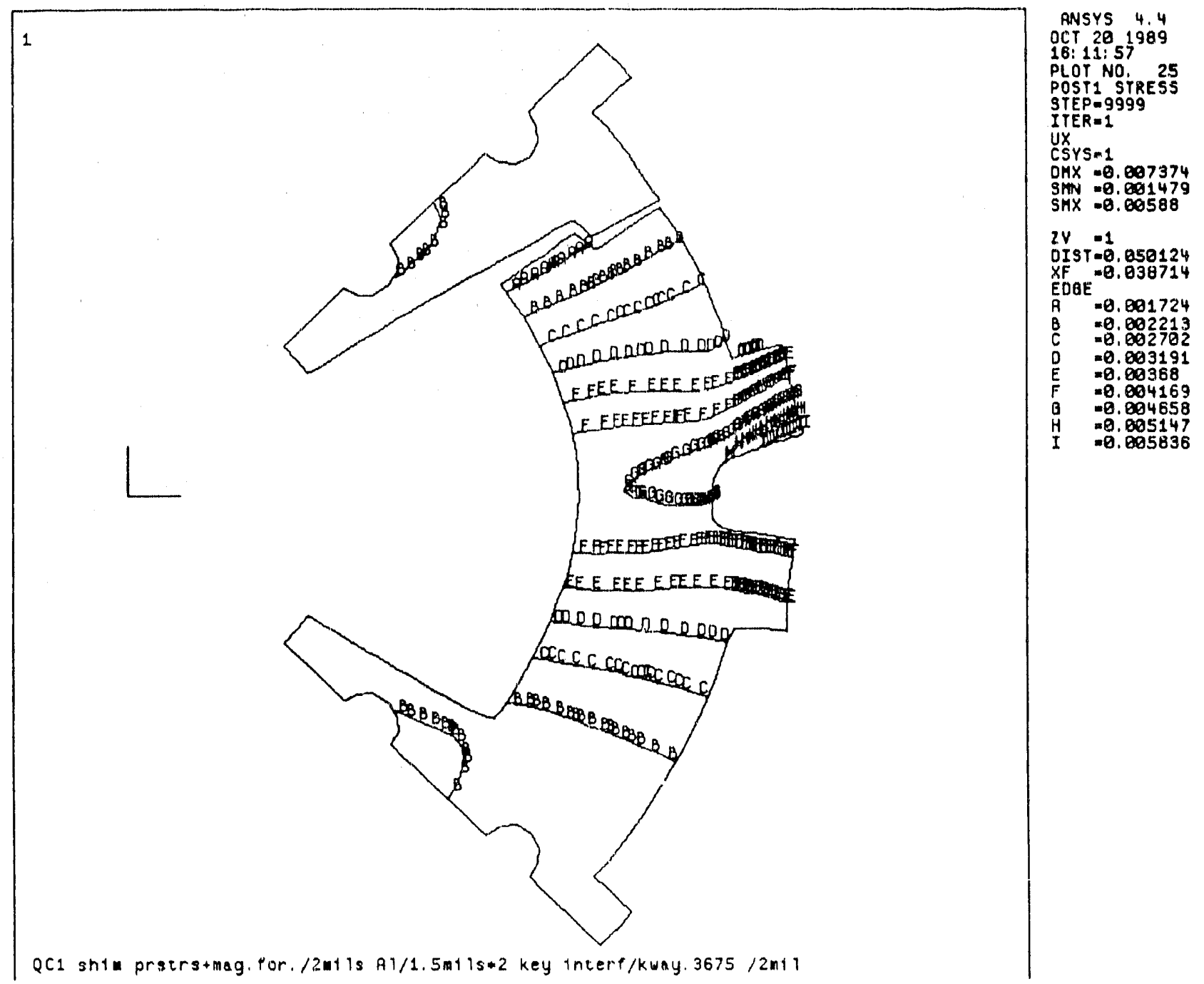

Fig. 19: radial displacements of the collar with prestress and Lorentz forces (inch) 


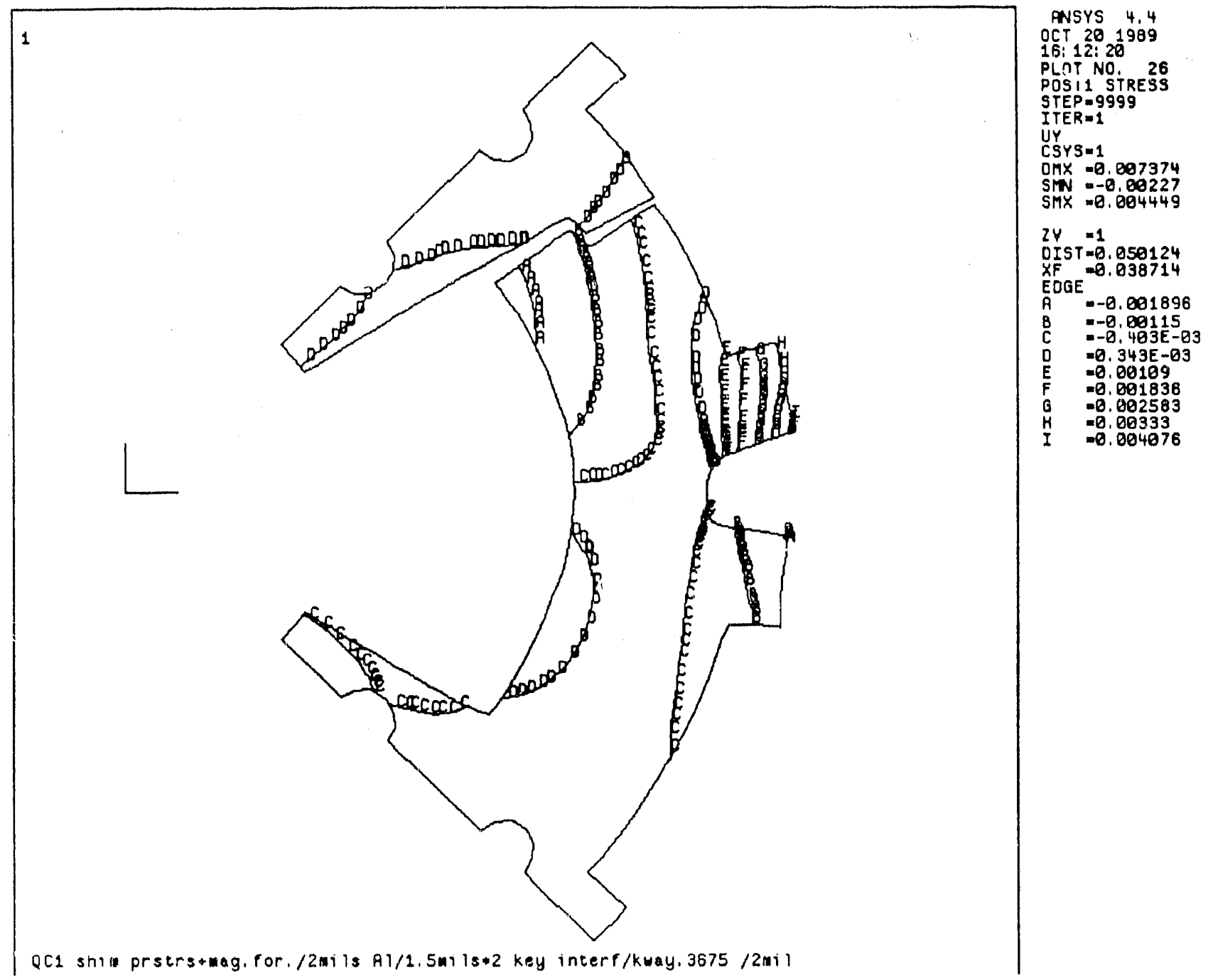

Fig. 20: azimuthal displacements of the collar with prestress and Lorentz forces (inch) 


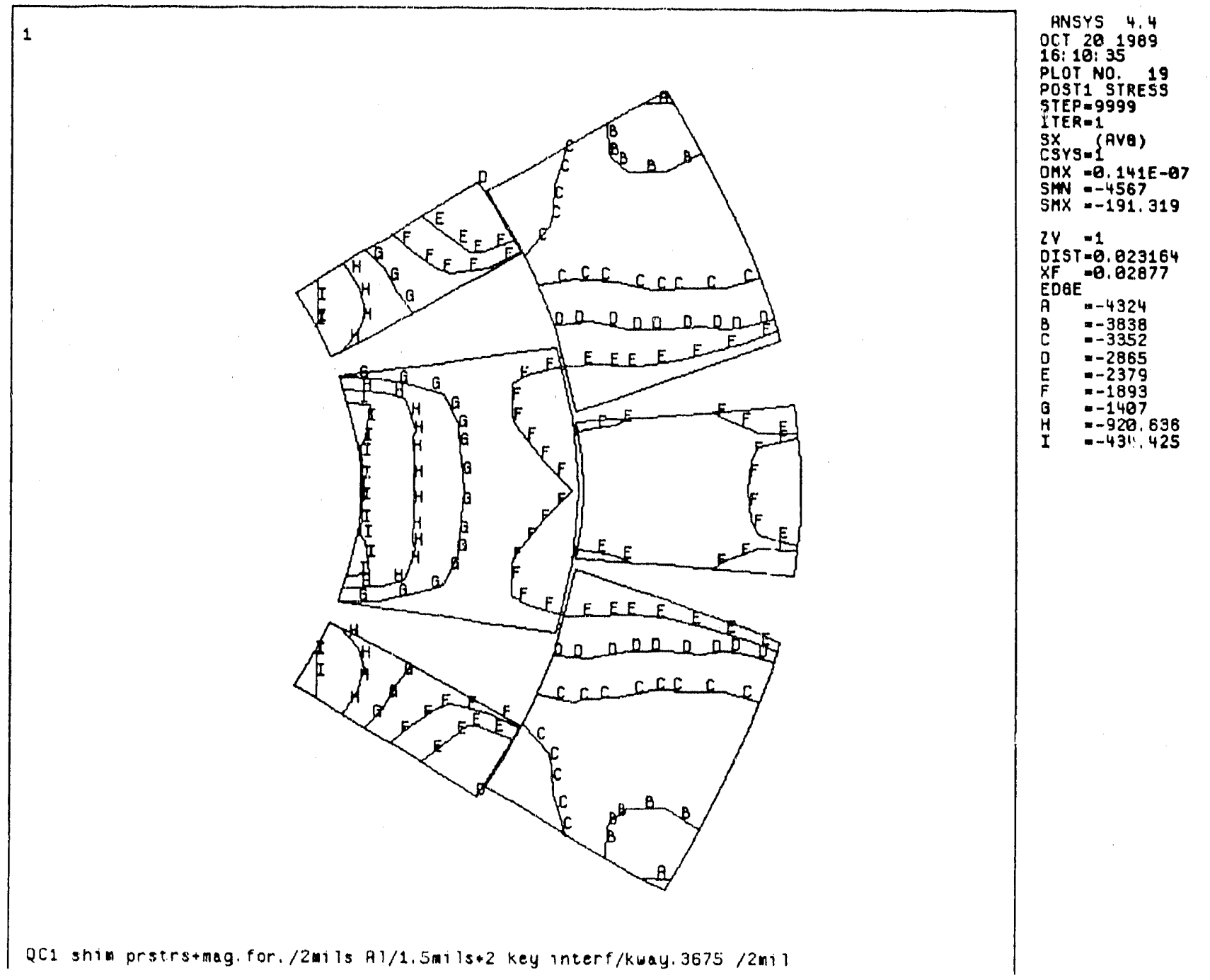

Fig. 21: radial stresses in the coils with prestress and Lorentz forces (psi) 


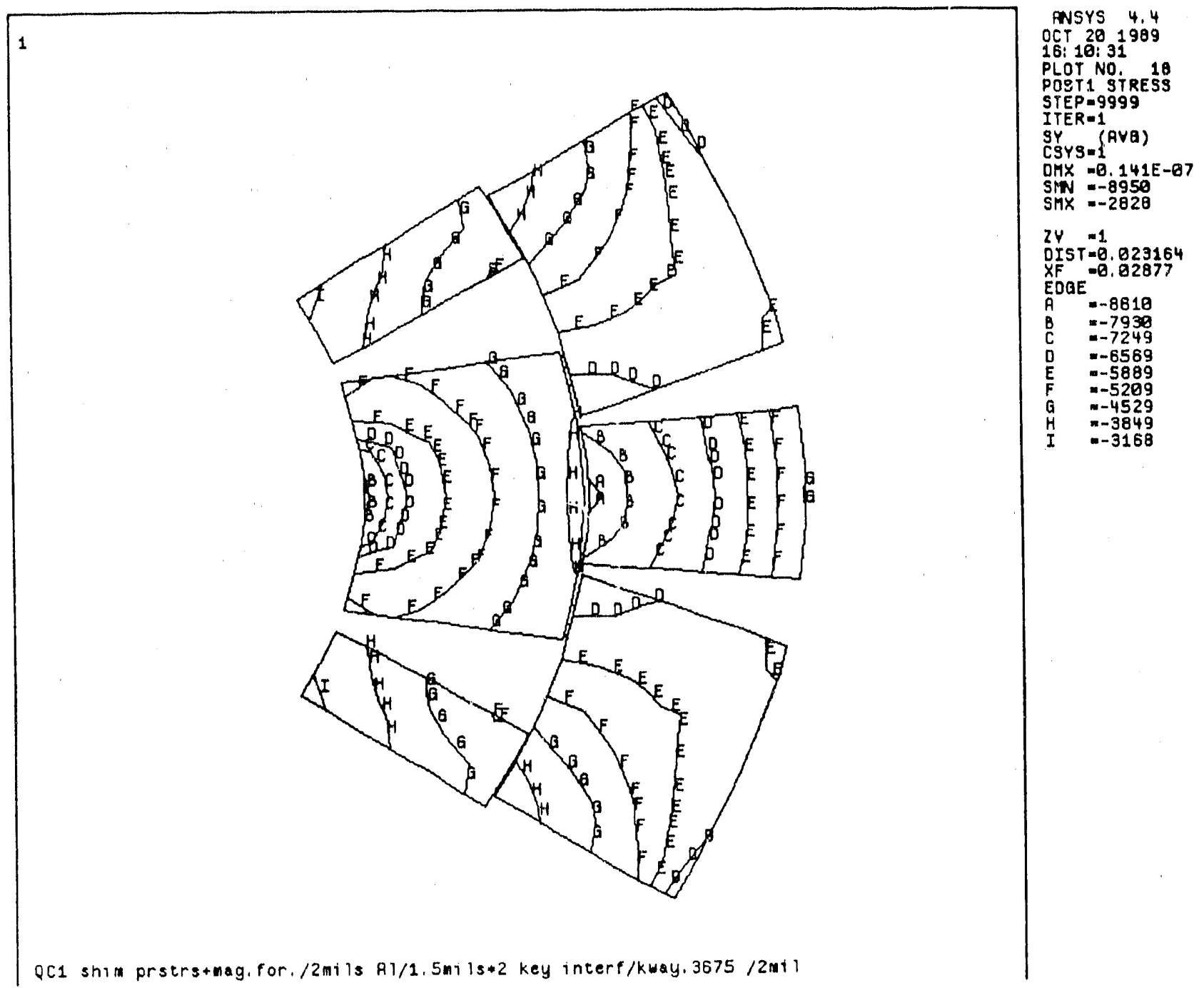

Fig. 22: azimuthal stresses in the coils with prestress and Lorentz forces (psi) 


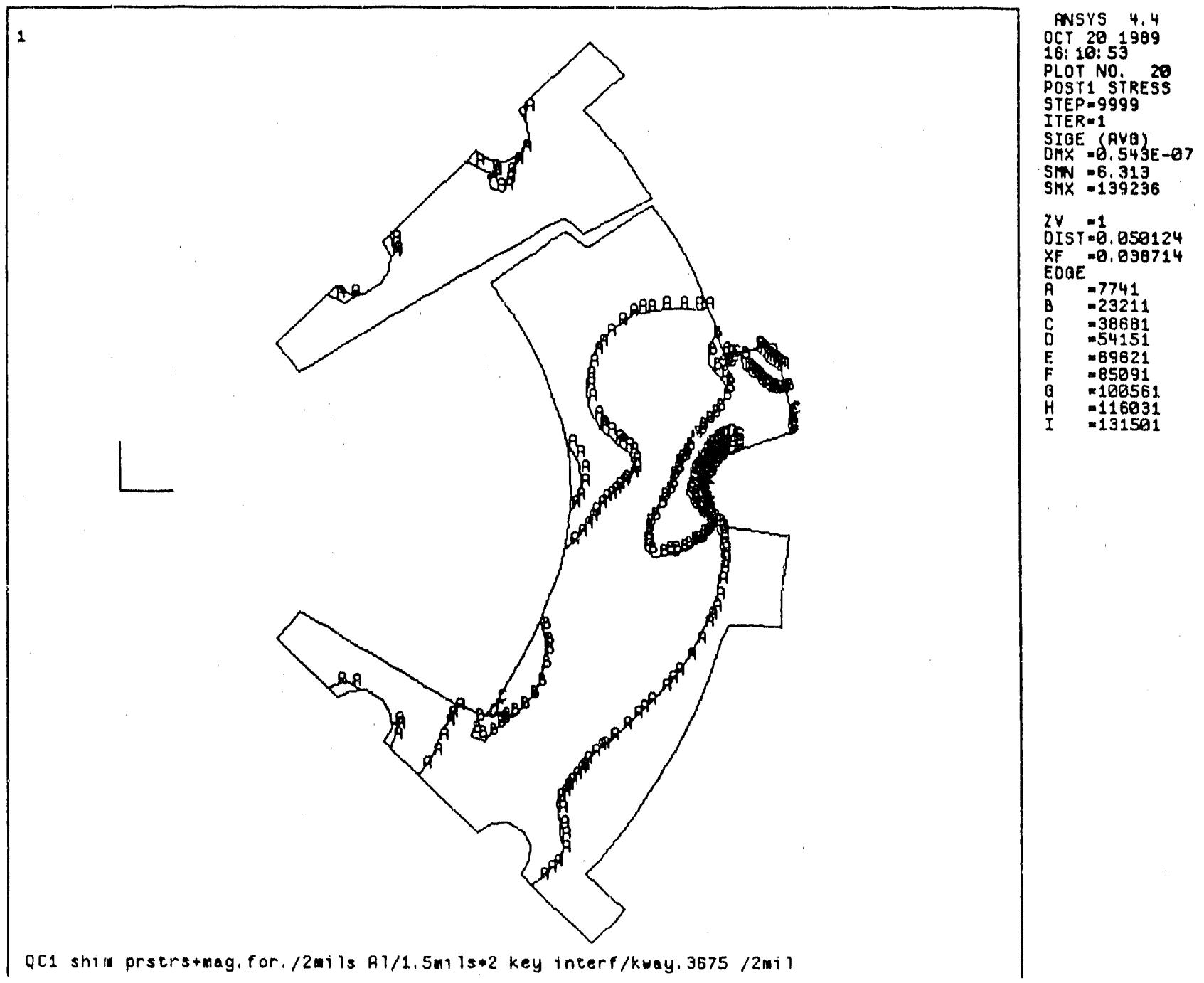

Fig. 23: Von Mises stress in the collar with prestress and Lorentz forces (psi) 


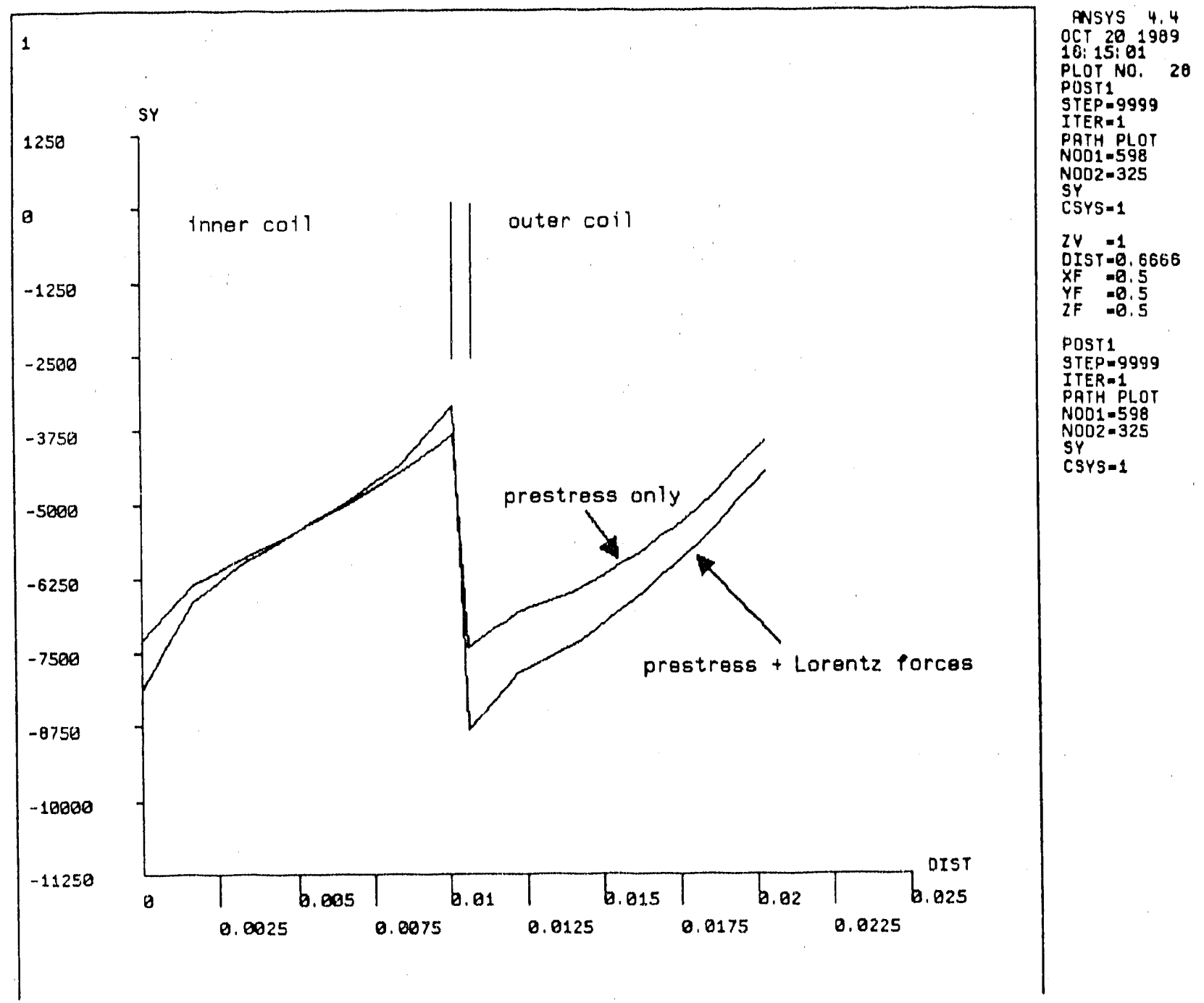

Fig. 24: azimuthal stress at the middle plane of the coils (psi) 


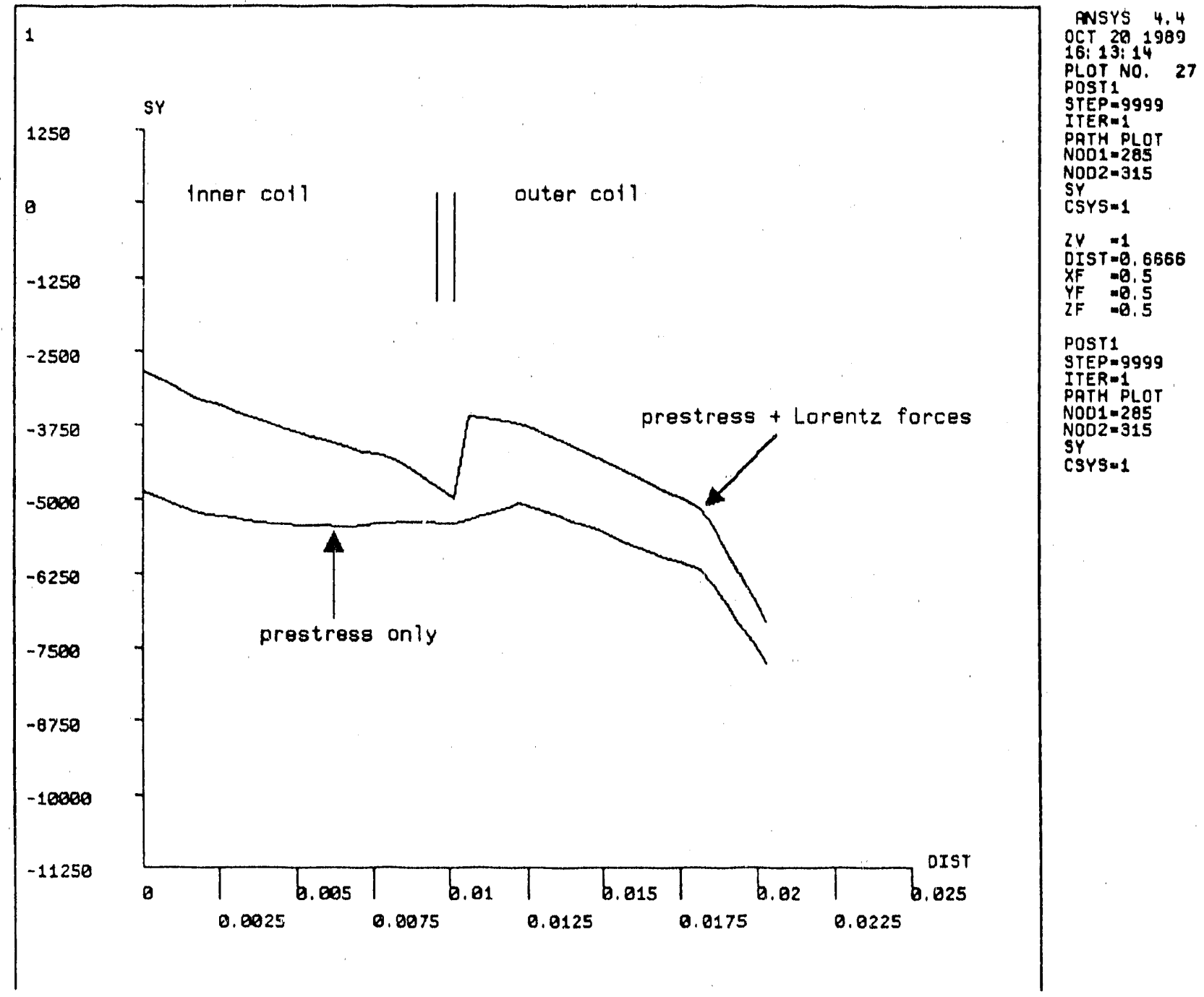

Fig 25: azimuthal stress at the poles (psi) 


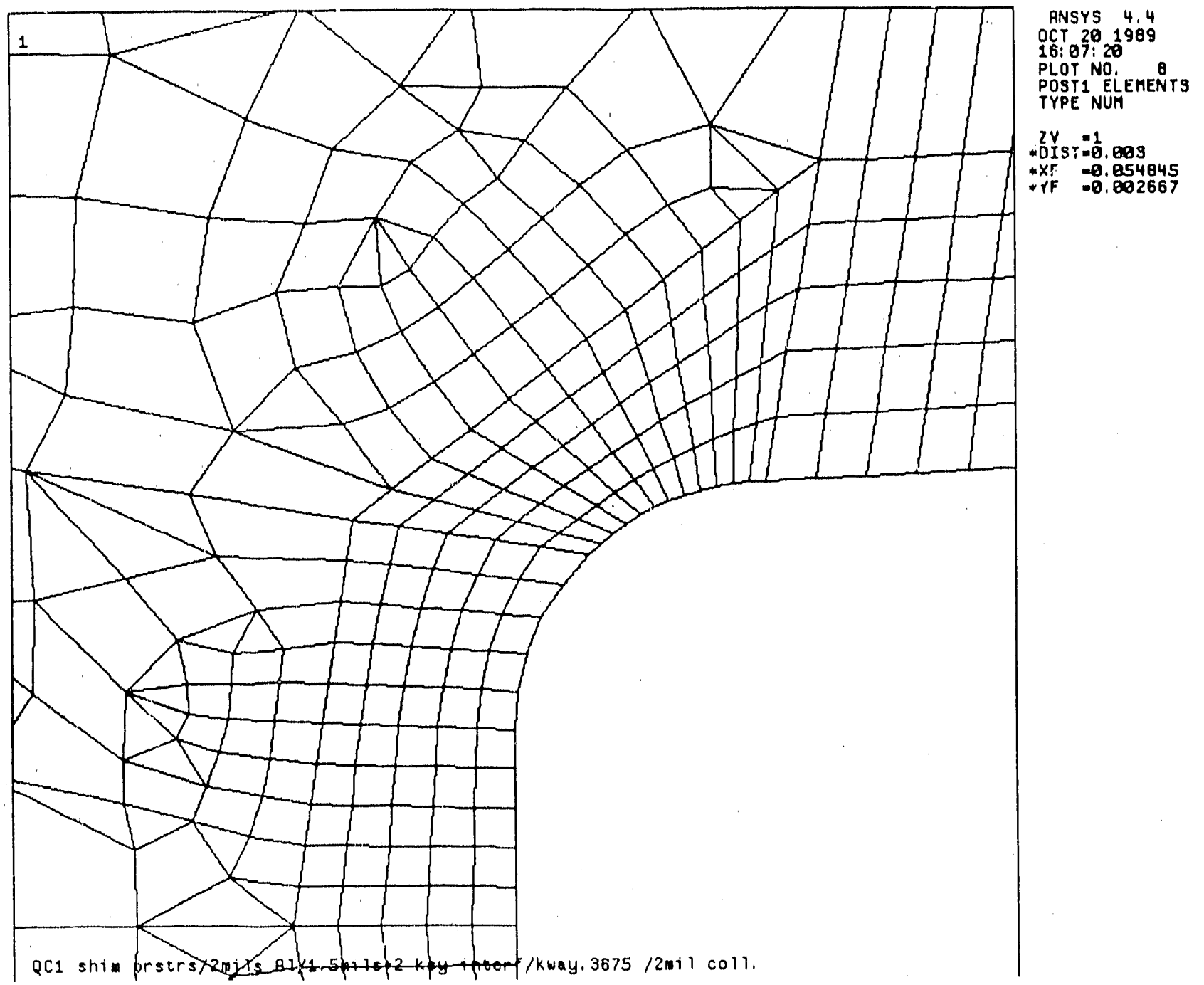

Fig. 26: detail of the mesh near the keyway 


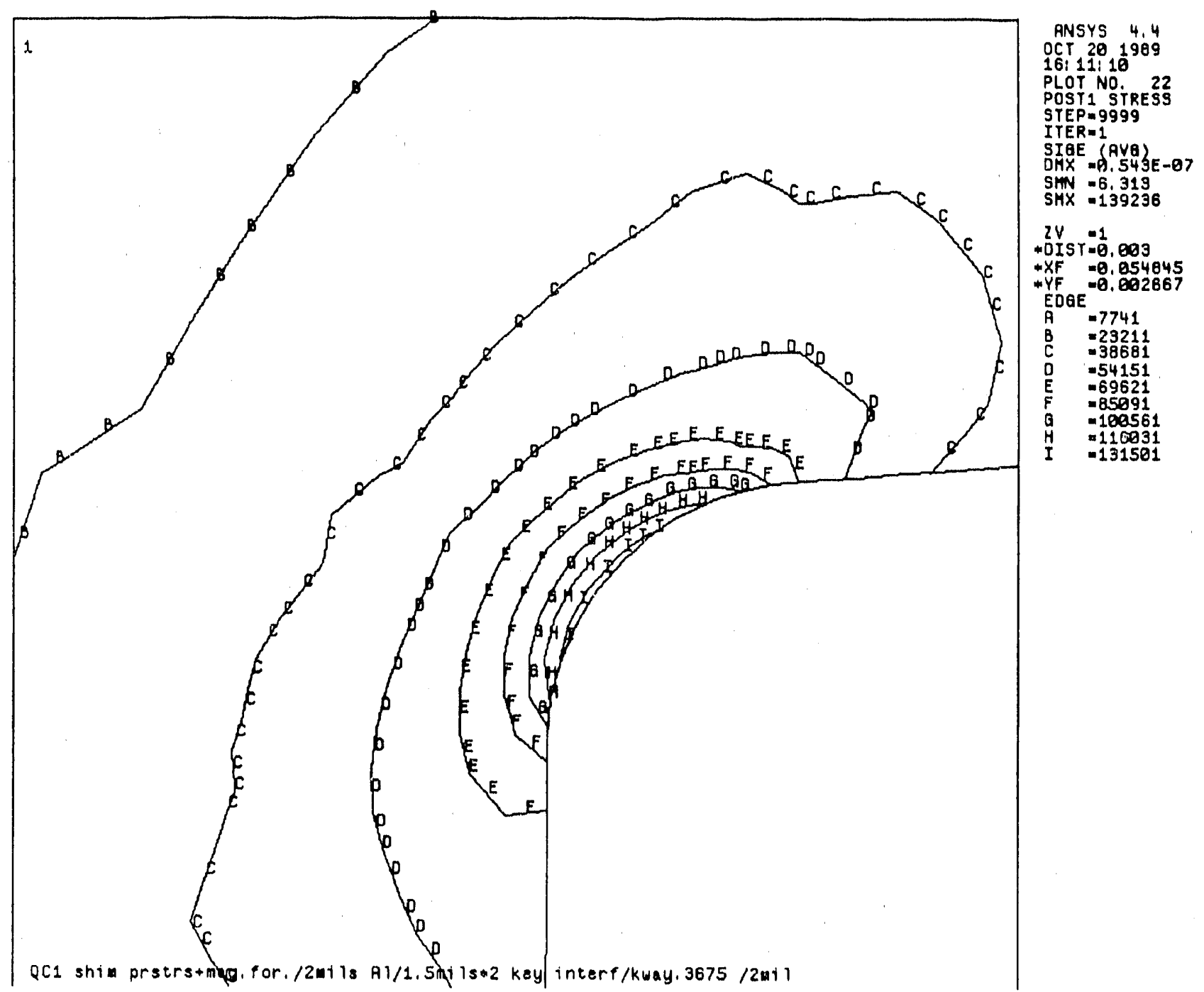

Fig. 27: Von Mises stress in the keyway with prestress and Lorentz forces (psi) 


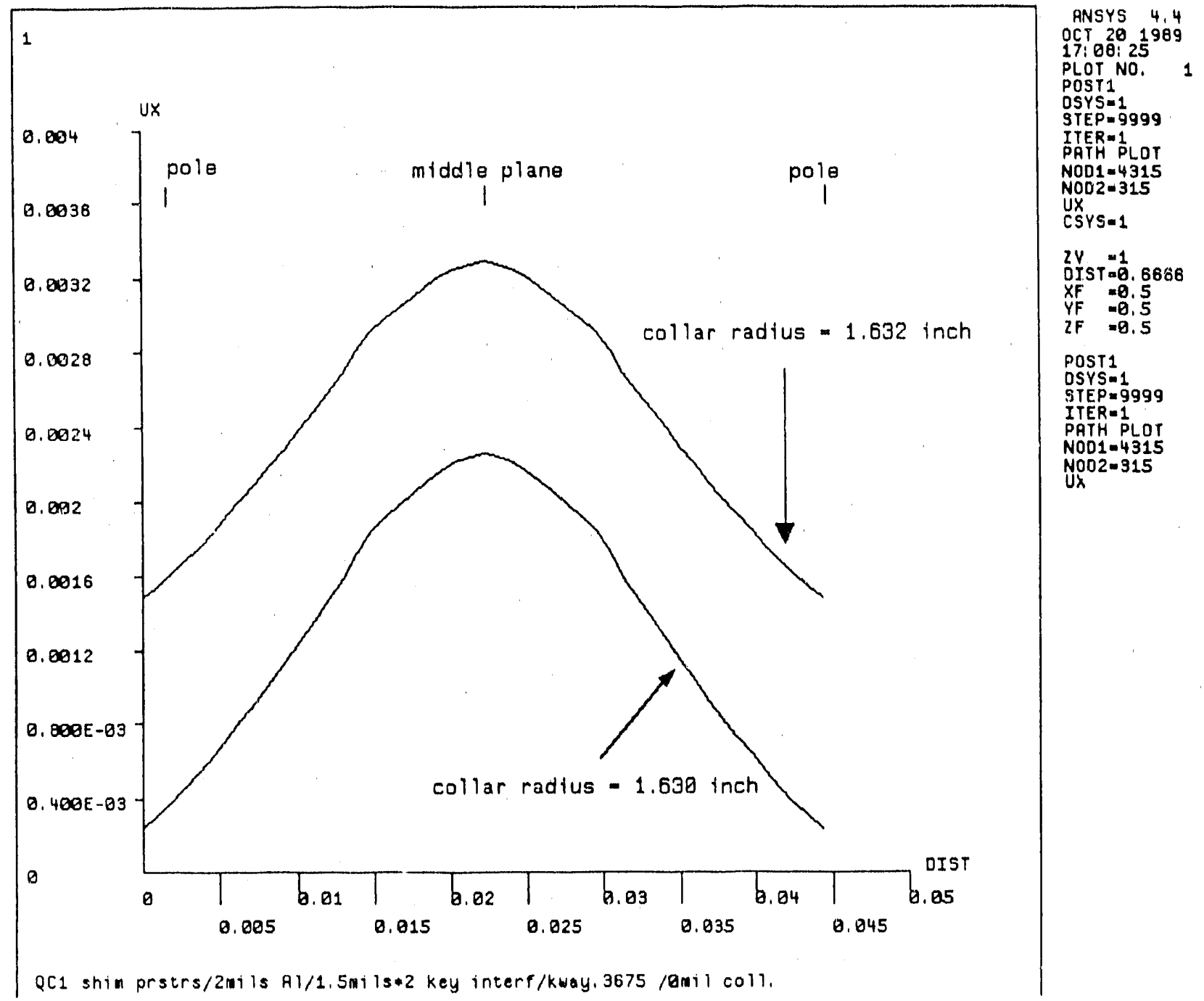

Fig. 28: radial displacement of the outer coil with two different collar radii (inch) 


\section{CONCLUSIONS}

It has been proven that ANSYS $\circledast$ is a very useful tool to perform in a fast and efficient way the two dimensional mechanical and magnetic analysis of a superconducting magnet. It can also be applied to analyze the magnet ends.

Now it is possible to focus the attention to the design of the magnets and not only to their analysis. This can be done using the parametric modeling and the optimization module of ANSYS®.

The results found in this paper will be compared to the experimental measurements on the QC model which include collar displacements under prestress and the coils pressure at the pole with and without the Lorentz forces.

\section{REFERENCES}

[1] D. Dell'Orco, Finite element analysis of the QA1 quadrupole magnet for the Superconducting Super Collider, Lawrence Berkeley Laboratory, SC-MAG-259.

[2] D. Dell'Orco, Finite element analysis of the QB quadrupole magnet for the Superconducting Super Collider, Lawrence Berkeley Laboratory, SCMAG-242.

[3] S. Caspi, A SSC Arc quadrupole with 21 turns, Lawrence Berkeley Laboratory, SSC-MAG-247.

[4] J. A. Swanson, G. De Salvo, ANSYS Users Manual, Swanson Analysis Systems Inc. P. O. Box 65, Houston, PA 15342 

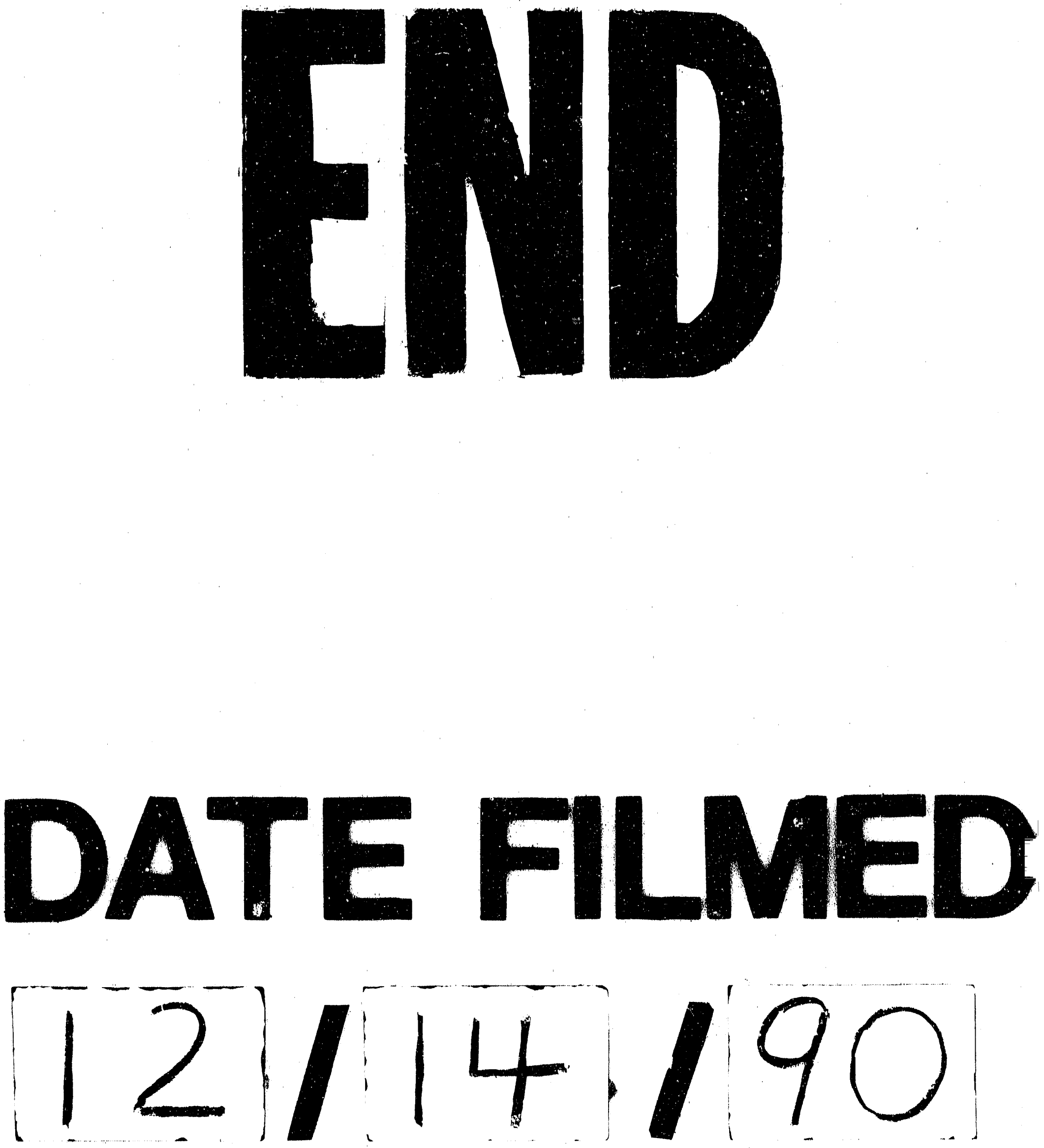